\title{
Synthesis of 3-Arylidene and 3-Arylimine Oxindole Derivatives and Evaluation of Their Src Kinase Inhibitory and Antiproliferative Activities
}

\author{
Shaya Mokhtari1§, Amir Nasrolahi Shirazi ${ }^{2,3 \S}$, Rakesh Kumar Tiwari²,3, Keykavous Parang ${ }^{2,3},{ }^{*}$ and Farzad Kobarfard ${ }^{4 *}$ \\ ${ }^{1}$ Central Research Laboratories, Shaheed Beheshti University of Medical Sciences, Tehran, Iran \\ ${ }^{2}$ Chapman University School of Pharmacy, Irvine, CA, 92618, United States of America \\ ${ }^{3}$ Chao Family Comprehensive Cancer Center, School of Medicine, University of California, Irvine, Shanbrom Hall, 101 The City Drive, Orange, CA 92868, United States \\ of America \\ ${ }^{4}$ Department of Medicinal Chemistry, School of Pharmacy, Shaheed Beheshti University of Medical Sciences, Tehran, Iran
}

\begin{abstract}
A number of novel 3-arylilidene and 3-arylimine-2-oxindole derivatives were synthesized, and their Src kinase inhibitory activities and antiproliferative activities were evaluated. Several compounds exhibited Src kinase inhibitory activity with $\mathrm{IC}_{50}$ values in the range of 5.3 to $211.8 \mu \mathrm{M}$. Compound $\mathrm{b}_{11}$ in 3-arylimine-2-oxindoles showed $\mathrm{IC}_{50}$ values of $5.3 \mu \mathrm{M}$ against Src kinase. Compounds $\mathrm{a}_{8}, \mathrm{a}_{20}, \mathrm{a}_{38}$, and $\mathrm{b}_{15}$ showed consistently>50\% proliferation inhibition against all three cancer cell lines at a concentration of $50 \mu \mathrm{M}$.
\end{abstract}

Keywords: Arylilidene; Arylimine; Cytotoxicity; Indole; Src kinase

\section{Introduction}

Protein tyrosine kinases (PTKs) are a group of enzymes, which catalyze the transfer of the $\gamma$-phosphate group of ATP to tyrosine residues of proteins. PTKS play critical roles in signal transduction and cellular biochemical pathways [1]. The level of cell tyrosine phosphorylation in different proteins is normally controlled by PTKs and tyrosine phosphatases. c-Src (Src kinase) is a non-receptor PTK and an early upstream signal transduction enzyme that is activated or overexpressed in several human cancers, such as breast, lung, colon, esophagus, skin, cervix, and gastric tissues [2,3]. Thus, inhibition of c-Src kinase has become a strategy for therapeutic intervention for different types of cancer.

Several studies have provided compelling evidence that Src kinase plays a crucial role in osteoclast function [4]. Thus, Src kinase is also a potential pharmacologic target for the treatment of bone loss diseases, such as osteoporosis $[5,6]$.

Based on the mechanism of action, current available Src kinase inhibitors can be classified into two major groups [7]: Inhibitors that compete with ATP for its binding pocket and inhibitors that work by interfering protein-protein interactions between the enzyme and its protein substrate. Competitive ATP binding site Src kinase inhibitors have shown to be more promising in terms of their potency and therapeutic applications. Several heterocyclic compounds have been used as competitive ATP binding site inhibitors, such as pyrazolo $(3,4-d)$ pyrimidine (PP1), pyrrolo(2,3-d)pyrimidine (CGP76030), pyrido(2,3-d)pyrimidines (PP-166285), quinolinecarbonitrile (compound I), and indolinone derivatives (Figure 1) [8-11].

Pyrazolopyrimidine derivatives including PP1 and PP2 were found to be highly potent Src kinase inhibitors with $\mathrm{IC}_{50}$ values in the nanomolar range. Indole derivatives such as SU6656 and SU6657 have been also reported as selective and potent Src-inhibitors with $\mathrm{IC}_{50}$ values in the nanomolar range [12]. Recently, a number of 1,3-dihydroindole2-one derivatives were reported to show Src and Yes tyrosine kinase inhibitory potency [13]. Olgen et al. have previously discovered 1-benzylindole-2-piperidinoethyl carboxylate, as a potent inhibitor of Src with $\mathrm{IC}_{50}$ value of $1.4 \mu \mathrm{M}$ [14]. They have also reported a series of 3-(substituted-benzylidene)-1,3-dihydroindoline-2-thione derivatives and the corresponding indoline-2-one congeners for their ability to inhibit Src kinase [15].

More recently, Kilic et al. investigated a number of $\mathrm{N}$-benzyl-5- phenyl indole-3-imine compounds and their corresponding amine congeners as Src kinase inhibitors. Among them, 1-(1-benzyl-5phenyl-1H-indole-3-yl)-(4-fluorobenzyl) methanamine hydrochloride (Figure 1) was reported as promising Src kinase inhibitor with an $\mathrm{IC}_{50}$ value of $4.7 \mu \mathrm{M}[16]$.

In continuation of our efforts to synthesize Src kinase inhibitors using new scaffolds and to investigate novel chemical structures as Src kinase inhibitors [17-21], a group of 3-arylilidene substituted oxindoles (a) and 3-arylimine substituted oxindoles (b) (Figure 2) were synthesized and evaluated for their inhibitory activity against Src kinase. We investigated the effect of various substituents in arylilidene and arylimine moieties at position 3 of the indole-2-one scaffold.

\section{Experimental Protocols}

\section{General}

All solvents, reagents and catalysts were purchased in analytical grade and used without further purification. The melting points $\left({ }^{\circ} \mathrm{C}\right)$ were determined by open capillary method on an electrothermal melting point apparatus and were uncorrected. The purity of compounds was confirmed by thin layer chromatography using WhatmanSil G/UV254 silica gel plates as the stationary phase and with suitable mobile phase with fluorescent indicator, and the spots were visualized under 254 and $366 \mathrm{~nm}$ illumination. Infrared spectra were recorded as thin films on $\mathrm{KBr}$ plates with $v_{\max }$ in inverse centimeters. ${ }^{1} \mathrm{H}$ NMR spectra were recorded on a Bruker DRX-Avance $(500 \mathrm{MHz})$ and

*Corresponding authors: Keykavous Parang, Chapman University School of Pharmacy, 9401 Jeronimo Road, Irvine, CA 92618, USA, Tel: +1-714-516-5489; Fax: +1-714-516-5481; E-mail: parang@chapman.edu;

Farzad Kobarfard, Department of Medicinal Chemistry, School of Pharmacy, Shaheed Beheshti University of Medical Sciences, Vali-e Asr Ave, Niayesh Junction, PO Box 14155-6153, Tehran, Iran, Tel: +98-21-88200092; Fax: +98-2188665341; E-mail: kobarfard@sbmu.ac.ir

$\S$ Shaya Mokhtari, Amir Nasrolahi Shirazi contributed equally to this work.

Received May 04, 2015; Accepted June 14, 2015; Published June 16, 2015

Citation: Mokhtari S, Shirazi AN, Tiwari RK, Parang K, Kobarfard F (2015) Synthesis of 3-Arylidene and 3-Arylimine Oxindole Derivatives and Evaluation of Their Src Kinase Inhibitory and Antiproliferative Activities. Med chem 5: 242-252. doi:10.4172/2161-0444.1000271

Copyright: (c 2015 Mokhtari S, et al. This is an open-access article distributed under the terms of the Creative Commons Attribution License, which permits unrestricted use, distribution, and reproduction in any medium, provided the original author and source are credited. 
<smiles>CC(C)(C)n1nc(-c2ccccc2)c2c(N)ncnc21</smiles><smiles>CC(C)(C)n1nc(-c2ccc(Cl)cc2)c2c(N)ncnc21</smiles>

\section{Pyrazolopyrimidine} $\mathrm{PP}_{1}$<smiles>C/C=C\C=C/c1ccc(OCCNCCOC)cc1</smiles>

Pyrrolopyrimidine CGP76030<smiles>COCCNCc1cn(Cc2ccccc2)c2ccc(-c3ccccc3)cc12</smiles>

$N$-benzyl-5-phenyl indole-3-imine Derivative

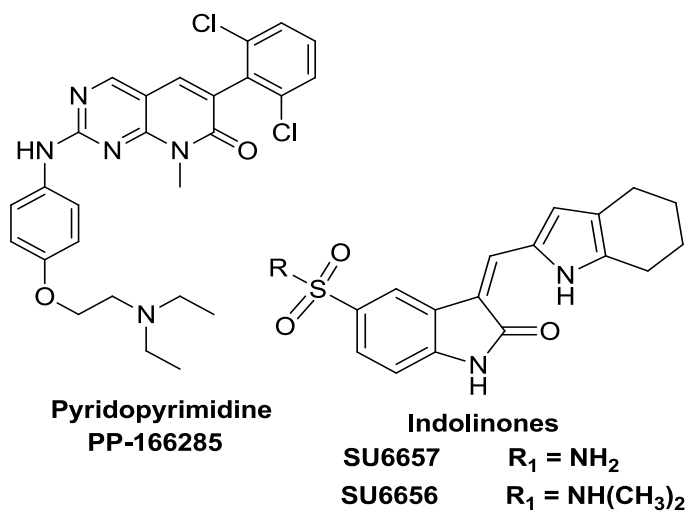<smiles>CNS(=O)(=O)c1ccc2c(c1)/C(=C/c1[nH]c3c(c1CCCN(C)C)CCCC3)C(=O)N2</smiles>

Quinoline Carbonitrile Derivative

Indolinone

Figure 1: The chemical structure of ATP competitive Src kinase inhibitors.<smiles>[R]c1ccc2c(c1)NC(=O)/C2=C/[Al]</smiles>

a<smiles></smiles>

b
Figure 2: General structures for 3-arylilidene substituted oxindoles (a) and 3-arylimine substituted oxindoles (b).

or $(250 \mathrm{MHz})$ spectrometer using DMSO- $d_{6}$ and $\mathrm{CDCl}_{3}$ as solvents and chemical shift values are expressed in ppm (parts per million) relative to tetramethylsilane (TMS) as internal standard; $s=$ singlet, $d=$ doublet, $\mathrm{dd}=$ double doublet, $\mathrm{t}=$ =triplet, $\mathrm{q}=$ quartet, $\mathrm{m}=$ multiplet, and $\mathrm{br} \mathrm{s}=$ broad singlet. Mass analyses were performed with an Agilent 6400 Series mass spectrometer equipped with an electrospray ionization source (capillary voltage at $4000 \mathrm{~V}$, nebulizing gas temperature at $300^{\circ} \mathrm{C}$, nebulizing gas flow at $12 \mathrm{~L} / \mathrm{min}$ ). All the compounds were analyzed for $\mathrm{C}, \mathrm{H}, \mathrm{N}$, and $\mathrm{S}$ on a Costech model 4010 and agreed with the proposed structures within $\pm 0.4 \%$ of the theoretical values [22-25].

General procedure for synthesis of 3-(substituted benzylidenyl)indolin-2-one analogues (compounds $\left.\mathbf{a}_{1}-\mathbf{a}_{42}\right)$ : A reaction mixture of the proper oxindole ( 1 equiv), aldehyde (1.2 equiv), and piperidine ( 0.1 equiv) in ethanol (1-2 mL/1 $\mu \mathrm{mol}$ oxindole) was stirred at $90^{\circ} \mathrm{C}$ for $3-5$ $\mathrm{h}$ [16]. After the mixture cooled, the precipitate was filtered, washed with cold ethanol and hexane and recrystallized from ethanol to give the target compound.

Preparation of 4 -(bromomethyl)benzonitrile $\left(a_{30-1}\right): 4$-Tolunitrile
(0.1 mol) was added to a flask containing $\mathrm{N}$-bromosuccinimide $(0.11$ mol) and dibenzoyl peroxide $(500 \mathrm{mg}$ ) in dried carbon tetrachloride $(200 \mathrm{ml})$. The reaction mixture was refluxed under nitrogen atmosphere overnight. Then the mixture cooled and filtered and the filtrate was concentrated and $300 \mathrm{ml}$ hexane was added to this solution to form the white crystals of 4-(bromomethyl)benzonitrile [26]. The product was purified by recrystallization from chloroform. The Yield: was $50 \%$, $\mathrm{mp}=113-115^{\circ} \mathrm{C}($ lit $\mathrm{mp}=115-117)$.

Preparation of 4-((4-methylpiperazin-1-yl)methyl)benzonitrile $\left(\mathbf{a}_{30-2}\right)$ : 1-(Bromo)toluenitrile $(10.2 \mathrm{mmol})$ in $20 \mathrm{~mL}$ of chloroform was stirred at room temperature before dropwise addition of a solution of 1-methyl piperazine $(28 \mathrm{mmol})$ in $5 \mathrm{~mL}$ chloroform. The reaction mixture was stirred at room temperature for 24 hours and the reaction was then quenched with water and further stirred for $30 \mathrm{~min}$ before extracting with chloroform. The organic layer was dried and concentrated [27]. In the residue, formed crystals were washed with hexane to give pure 4-((4-methylpiperazin-1-yl)methyl) benzonitrile; Yield: $(35 \%), \mathrm{mp}=65-67^{\circ} \mathrm{C}$ (lit $\mathrm{mp}=62-64^{\circ} \mathrm{C}$ ); ESI-MS: Observed $[\mathrm{M}+\mathrm{H}]^{+}=216$. Calculated for $\mathrm{C}_{13} \mathrm{H}_{17} \mathrm{~N}_{3}=215.2$.

Preparation of 4-((4-methylpiperazin-1-yl) methyl) benzaldehyde $\left(\mathrm{a}_{30-3}\right)$ : 4-((4-Methylpiperazin-1-yl)methyl)benzonitrile (9 mmol) was dissolved in formic acid $75 \%(37 \mathrm{~mL})$ and raney nickel alloy $(2 \mathrm{~g})$ was added to this solution. The mixture was refluxed for $2 \mathrm{~h}$, filtered over celite, and washed with $20 \mathrm{~mL}$ of cold ethanol $96^{\circ} \mathrm{C}$ [28]. The filtrate was concentrated to half of its volume and filtered again to remove the green colloidal impurities to give $(1.8 \mathrm{~g})$ crude product in the filtrate, ESI-MS: Observed $[\mathrm{M}+\mathrm{H}]^{+}=219$. Calculated for $\mathrm{C}_{13} \mathrm{H}_{18} \mathrm{~N}_{2} \mathrm{O}=218.29$.

Synthesis of 3-(4-((4-methylpiperazin-1-yl)methyl) benzylidene)indolin-2-one $\left(a_{30}\right)$ : A mixture of oxindole (1 equiv), 4-((4-methylpiperazin-1-yl) methyl)benzaldehyde $\left(\mathrm{a}_{30-3}\right)$ (1.2 equiv), 
and piperidine ( 0.1 equiv) in ethanol $(1-2 \mathrm{~mL} / 1 \mu \mathrm{mol}$ oxindole) was stirred at $90^{\circ} \mathrm{C}$ overnight. The solvent was evaporated, and the residue was dissolved in warm ethyl acetate and passed through a column of silica gel. The polarity of eluting solvent was increased with the addition of methanol to the ethyl acetate. The yellow liquid phase was collected and the solvent was evaporated to achieve 3-(4-((4-methylpiperazin-1yl)methyl)benzylidene) indolin-2-one.

General Procedure for synthesis of Compounds $b_{1}-b_{24}$ : A mixture of indole-2, 3-dione $(0.01 \mathrm{M})$ and amine $(0.01 \mathrm{M})$ in absolute ethanol $(20 \mathrm{ml})$ was refluxed for $20 \mathrm{~h}$ in the presence of 2-3 drops of glacial acetic acid [24]. After cooling, the mixture was filtered and washed with hexane and recrystallized from ethanol to give compounds $b_{1}-b_{24}$

(E)-3-Benzylideneindolin-2-one $\left(\mathbf{a}_{1}\right)$ : Yield: $23 \%$; $\mathrm{mp}: 174-175^{\circ} \mathrm{C}$ (dec.), ethanol; IR (KBr) $v_{\max } 3203(\mathrm{~N}-\mathrm{H}), 1716(\mathrm{C}=\mathrm{O}) \mathrm{cm}^{-1} ;{ }^{1} \mathrm{H}$ NMR (500 MHz, DMSO-d $)$ ) 9.08 (s, 1H, NH-1), 7.9 (s, 1H, H-vinyl), 7.72 (d, 2H, J=7.3 Hz, H-2', 6'), 7.68 (d, 1H, J=7.8 Hz, H-4), 7.51 (m, 3H, H-3', 4', 5' ), $7.26(\mathrm{dt}, \mathrm{J}=7.8 \mathrm{~Hz}, 1 \mathrm{~Hz}, 1 \mathrm{H}, \mathrm{H}-6), 6.98(\mathrm{~d}, 1 \mathrm{H}, \mathrm{J}=7.8 \mathrm{~Hz}, \mathrm{H}-7)$, $6.91(\mathrm{dt}, 1 \mathrm{H}, \mathrm{J}=7.6 \mathrm{~Hz}, 0.87, \mathrm{H}-5)$; ESI-MS: Observed $[\mathrm{M}+\mathrm{H}]^{+}=222$. Calculated for $\mathrm{C}_{15} \mathrm{H}_{11} \mathrm{NO}=221$; Anal. Found: $\mathrm{C}, 81.2 ; \mathrm{H}, 5.02 ; \mathrm{N}, 6.21$; O, 6.99. Calculated: C, 81.43; H, 5.01; N, 6.33; O, 7.23\%.

3-(4-Hydroxybenzylidene)indolin-2-one ( $\left.\mathbf{a}_{2}\right)$ : Yield: 38\%; $\mathrm{mp}$ : $295-298^{\circ} \mathrm{C}$ (dec.) (lit $\left.\mathrm{mp}>300^{\circ} \mathrm{C}\right)$ [17], ethanol; IR (KBr) $v_{\max } 3196(\mathrm{~N}-$ $\mathrm{H}), 1668(\mathrm{C}=\mathrm{O}) \mathrm{cm}^{-1}$; ESI-MS: Observed $[\mathrm{M}+\mathrm{H}]^{+}=237.9,[\mathrm{M}+\mathrm{Na}]^{+}=259$. Calculated for $\mathrm{C}_{15} \mathrm{H}_{11} \mathrm{NO}_{2}=237$; Anal., found: 75.91; $\mathrm{H}, 4.63 ; \mathrm{N}, 5.92 ; \mathrm{O}$, 13.51. Calculated: C, 75.94; H, 4.67; N, 5.90; O, 13.49\%.

3-(4-Methoxybenzylidene)indolin-2-one $\left(\mathbf{a}_{3}\right)$ : Yield: 23\%; mp: $155.5-159^{\circ} \mathrm{C}$ (lit $\left.\mathrm{mp}=156-157^{\circ} \mathrm{C}\right)$ [22,23], ethanol; IR (KBr) $v_{\max }$ $3144(\mathrm{~N}-\mathrm{H}), 1697(\mathrm{C}=\mathrm{O}) \mathrm{cm}^{-1}$; ESI-MS: Observed $\left(\mathrm{M}+\mathrm{H}^{+}\right)=251.9$, $[\mathrm{M}+\mathrm{Na}]^{+}=273.9$. Calculated for $\mathrm{C}_{15} \mathrm{H}_{13} \mathrm{NO}_{2}=251$; Anal., found: $\mathrm{C}$, 76.45; H, 5.22; N, 5.54; O, 12.70. Calculated: C, 76.48; H, 5.21; N, 5.57; $\mathrm{O}, 12.73 \%$.

3-(3-Methoxybenzylidene)indolin-2-one $\left(\mathbf{a}_{4}\right)$ : Yield: 20\%; $\mathrm{mp}$ : 148.5- $150^{\circ} \mathrm{C}$, ethanol; IR $(\mathrm{KBr}) v_{\max } 3136(\mathrm{~N}-\mathrm{H}), 1711(\mathrm{C}=\mathrm{O}) \mathrm{cm}$ 1; ESI-MS: Observed $[\mathrm{M}+\mathrm{H}]^{+}=252,[\mathrm{M}+\mathrm{Na}]^{+}=274$. Calculated for $\mathrm{C}_{15} \mathrm{H}_{13} \mathrm{NO}_{2}=251$; Anal., found: $\mathrm{C}, 76.43 ; \mathrm{H}, 5.21 ; \mathrm{N}, 5.55 ; \mathrm{O}, 12.71$. Calculated for $\mathrm{C}_{15} \mathrm{H}_{13} \mathrm{NO}_{2}$ : C, 76.48; $\mathrm{H}, 5.21 ; \mathrm{N}, 5.57 ; \mathrm{O}, 12.73 \%$.

4-((2-Oxoindolin-3-ylidene) methyl)benzonitrile ( $\left.\mathbf{a}_{5}\right)$ : Yield: 40\%; mp: $231-233^{\circ} \mathrm{C}$, ethanol; IR ( $\left.\mathrm{KBr}\right) v_{\max } 3177(\mathrm{~N}-\mathrm{H}), 1704(\mathrm{C}=\mathrm{O})$, $1609 \mathrm{~cm}^{-1}$; ESI-MS: Observed $[\mathrm{M}+\mathrm{H}]^{+}=246.9, \quad[\mathrm{M}+\mathrm{Na}]^{+}=268.9$. Calculated for $\mathrm{C}_{16} \mathrm{H}_{10} \mathrm{~N}_{2} \mathrm{O}=246$; Anal., found: $\mathrm{C}, 78.00 ; \mathrm{H}, 4.1 ; \mathrm{N}, 11.35$; O, 6.48. Calculated: C, C, 78.03; H, 4.09; N, 11.38; O, 6.50\%.

(Z)-3-(4-Nitrobenzylidene) indolin-2-one $\left(\mathrm{a}_{6}\right)$ : Yield: $88 \%$; $\mathrm{mp}$ : 233.3-235. ${ }^{\circ} \mathrm{C}$, ethanol; IR (KBr) $v_{\max } 3150(\mathrm{~N}-\mathrm{H}), 1712(\mathrm{C}=\mathrm{O}) \mathrm{cm}^{-1}$; ${ }^{1} \mathrm{H} \mathrm{NMR}\left(500 \mathrm{MHz}, \mathrm{CDCl}_{3}\right) \delta: 8.38\left(\mathrm{~d}, 2 \mathrm{H}, \mathrm{J}=8.7 \mathrm{~Hz}, \mathrm{H}-3^{\prime}, 5^{\prime}\right), 7.85(\mathrm{~d}$, $2 \mathrm{H}, \mathrm{J}=8.7 \mathrm{~Hz}, \mathrm{H}-2$ ', 6'), 7.81 (s, 1H, H-8), 7.70 (bs, $1 \mathrm{H}, \mathrm{NH}-1), 7.48$ (d, $1 \mathrm{H}, \mathrm{H}-), 7.31$ (m, 1H, H-7), 6.93 (m, 2H, H-5, 6 ); ESI-MS: Observed $[\mathrm{M}+\mathrm{H}]^{+}=267$. Calculated for $\mathrm{C}_{15} \mathrm{H}_{10} \mathrm{~N}_{2} \mathrm{O}_{3}=266$; Anal., found: $\mathrm{C}, 67.65$; H, 3.77; N, 10.50; O, 18.01. Calculated: C, 67.67; H, 3.79; N, 10.52; O, $18.03 \%$.

(Z)-3-(3-Nitrobenzylidene) indolin-2-one $\left(\mathbf{a}_{7}\right)$ : Yield: 18\%; mp: 10-212 ${ }^{\circ} \mathrm{C}$, ethanol; IR $(\mathrm{KBr}) v_{\max } 3140(\mathrm{~N}-\mathrm{H}), 1695(\mathrm{C}=\mathrm{O}) \mathrm{cm}^{-1} ;{ }^{1} \mathrm{H}$ NMR $\left(500 \mathrm{MHz}_{1} \mathrm{CDCl}_{3}\right) \delta: 10.73(\mathrm{~s}, 1 \mathrm{H}, \mathrm{NH}-1), 9.39(\mathrm{~s}, 1 \mathrm{H}, \mathrm{H}-2 \mathrm{\prime}), 8.64(\mathrm{~d}$, $\left.1 \mathrm{H}, \mathrm{J}=7.7 \mathrm{~Hz}, \mathrm{H}-4^{\prime}\right), 8.27$ (d, 1H, J=8.2 Hz, H-6'), 7.96 (s, 1H, H-vinyl), 7.75 (m, 2H, H-, 6), 7.26 (t, 1H, J=7.6 Hz, H-5'), 7.02 (t, 1H, J=7.5 Hz, H-5 ), $6.85(\mathrm{~d}, 1 \mathrm{H}, \mathrm{J}=7.6 \mathrm{~Hz}, \mathrm{H}-4)$; ESI-MS: Observed $[\mathrm{M}+\mathrm{H}]^{+}=267$. Calculated for $\mathrm{C} 15 \mathrm{H} 10 \mathrm{~N} 2 \mathrm{O} 3=266$; Anal., found: C, 67.68; H, 3.81; N, 10.53; O, 18.05. Calculated: C, 67.67; H, 3.79; N, 10.52; O, 18.03\%.
3-(2-Nitrobenzylidene) indolin-2-one $\left(\mathbf{a}_{8}\right)$ : Yield: $10 \%$; $\mathrm{mp}$ : 28-231 ${ }^{\circ} \mathrm{C}$ (lit $\mathrm{mp}$ : for $\mathrm{Z}$ isomer $=239-240^{\circ} \mathrm{C}$ ) [24], ethanol; IR $(\mathrm{KBr})$ $v_{\max } 3142(\mathrm{~N}-\mathrm{H}), 1703(\mathrm{C}=\mathrm{O}) \mathrm{cm}^{-1}$; ESI-MS: Observed $[\mathrm{M}+\mathrm{H}]^{+}=267$, $[\mathrm{M}+\mathrm{Na}]^{+}=289$. Calculated for $\mathrm{C}_{15} \mathrm{H}_{10} \mathrm{~N}_{2} \mathrm{O}_{3}=266$; Anal., found: $\mathrm{C}$, 67.69; $\mathrm{H}, 3.80 ; \mathrm{N}, 10.52 ; \mathrm{O}, 18.04$. Calculated: C, 67.67; H, 3.79; N, 10.52; O, $18.03 \%$.

(E)-3-(4-(Methylthio)benzylidene)indolin-2-one $\quad\left(a_{9}\right)$ : Yield: 38\%; mp: 84-186 ${ }^{\circ} \mathrm{C}$, ethanol; IR (KBr) v $v_{\max } 3200(\mathrm{~N}-\mathrm{H}), 1700(\mathrm{C}=\mathrm{O})$ $\mathrm{cm}^{-1}$; ${ }^{1} \mathrm{H}$ NMR $\left(250 \mathrm{MHz}, \mathrm{DMSO}-\mathrm{d}_{6}\right) \delta 9.02(\mathrm{~s}, 1 \mathrm{H}, \mathrm{NH}-1), 7.82(\mathrm{~s}, 1 \mathrm{H}$, H-vinyl), 7.75 (d, 1H, J=7.7 Hz, H-4), 7.66 (d, 2H, J=8.4 Hz; H-2', 6'), 7.36 (d, 2H, J=8.3 Hz, H-3', 5'), 7.26 (t, 1H, J=7.5 Hz, H-6), 6.95 (d, 2H, $\mathrm{J}=7.7 \mathrm{~Hz}, \mathrm{H}-7), 6.93(\mathrm{t}, 1 \mathrm{H}, \mathrm{J}=7.7 \mathrm{~Hz}, \mathrm{H}-5), 2.59$ (s, 3H, CH$)_{3}$ ); ESI-MS: Observed $[\mathrm{M}+\mathrm{H}]^{+}=268$. Calculated for $\mathrm{C}_{16} \mathrm{H}_{13} \mathrm{NOS}=267$; Anal., found: C, 71.86, H, 4.92; N, 5.26; O, 5.99; S, 11.98. Calculated: C, 71.88; H, 4.90; N, 5.24; O, 5.98; S, $11.99 \%$.

(Z)-3-(Pyridin-2-ylmethylene) indolin-2-one $\left(\mathbf{a}_{10}\right)$ : Yield: $10 \%$; mp: 99.5-01.5 ${ }^{\circ} \mathrm{C}$, ethanol; IR (KBr) $v_{\max } 3194(\mathrm{~N}-\mathrm{H}), 1710(\mathrm{C}=\mathrm{O}) \mathrm{cm}^{-1}$; ${ }^{1} \mathrm{H}$ NMR $\left(500 \mathrm{MHz}, \mathrm{CDCl}_{3}\right) \delta: 9.06(\mathrm{~d}, 1 \mathrm{H}, \mathrm{J}=7.8 \mathrm{~Hz}, \mathrm{H}-3$ ') $7.85(\mathrm{~d}$, $\left.1 \mathrm{H}, \mathrm{J}=4.7 \mathrm{~Hz}, \mathrm{H}-6^{\prime}\right), 8.94$ (bs, $\left.1 \mathrm{H}, \mathrm{NH}-1\right), 7.84$ (dt, $1 \mathrm{H}, \mathrm{J}=1.8,7.7 \mathrm{~Hz}$, H-5'), 7.76(s, 1H, H-vinyl), 7.67 (d, 1H, J=7.8 Hz; H-4), 7.37 (t, 1H, $\mathrm{J}=7.8 \mathrm{~Hz}, \mathrm{H}-6), 7.35$ (m, 2H, H-4'), 7.1 (dt, 1H, J=0.9, $7.7 \mathrm{~Hz} ; \mathrm{H}-), 6.95$ $(\mathrm{d}, 1 \mathrm{H}, \mathrm{J}=7.7 \mathrm{~Hz}, \mathrm{H}-7)$; ESI-MS: Observed $[\mathrm{M}+\mathrm{H}]^{+}=223$. Calculated for $\mathrm{C}_{14} \mathrm{H}_{10} \mathrm{~N}_{2} \mathrm{O}=222$; Anal., found: $\mathrm{C}, 75.63 ; \mathrm{H}, 4.55 ; \mathrm{N}, 12.61 ; \mathrm{O}, 7.19$. Calculated for $\mathrm{C}_{14} \mathrm{H}_{10} \mathrm{~N}_{2} \mathrm{O}: \mathrm{C}, 75.66 ; \mathrm{H}, 4.54 ; \mathrm{N}, 12.60 ; \mathrm{O}, 7.20 \%$.

(Z)-3-(Pyridin-3-ylmethylene) indolin-2-one $\left(\mathbf{a}_{11}\right)$ : Yield: $23 \%$; mp: 92-194 ${ }^{\circ} \mathrm{C}$, ethanol; IR (KBr) v $3134(\mathrm{~N}-\mathrm{H}), 1706(\mathrm{C}=\mathrm{O}) \mathrm{cm}^{-1}$, ${ }^{1} \mathrm{H}$ NMR (500 MHz, $\mathrm{CDCl}_{3}$ ) $\delta 9.01$ (bs, $\left.1 \mathrm{H}, \mathrm{NH}-1\right), 8.97$ (s, 1H, H-2'), $8.72\left(\mathrm{dd}, 1 \mathrm{H}, \mathrm{J}=4.8,1.4 \mathrm{~Hz}, \mathrm{H}-4^{\prime}\right), 7.99(\mathrm{~d}, 1 \mathrm{H}, \mathrm{J}=7.9 \mathrm{~Hz}, \mathrm{H}-4) 7.79(\mathrm{~s}$, 1H, H-vinyl), 7.55 (d, 1H, J=7.7 Hz, H-6'), 7.47 (m, 1H, H-5'), $7.28(\mathrm{t}$, $1 \mathrm{H}, \mathrm{J}=8.9 \mathrm{~Hz}, \mathrm{H}-6), 6.97$ (d, $1 \mathrm{H}, \mathrm{J}=7.8 \mathrm{~Hz}, \mathrm{H}-7), 6.92(\mathrm{dt}, 1 \mathrm{H}, \mathrm{J}=7.8 \mathrm{~Hz}$, $\mathrm{H}-5)$; ESI-MS: Observed $[\mathrm{M}+\mathrm{H}]^{+}=223$. Calculated for $\mathrm{C}_{14} \mathrm{H}_{10} \mathrm{~N}_{2} \mathrm{O}=222$; Anal., found: C, 75.65; H, 4.54; N, 12.59; O, 7.19. Calculated: C, 75.66; $\mathrm{H}, 4.54 ; \mathrm{N}, 12.60 ; \mathrm{O}, 7.20 \%$.

(E)-3-(4-Fluorobenzylidene) indolin-2-one $\left(a_{12}\right)$ : Yield: 54\%; mp188-189.5 $5^{\circ}$, ethanol; IR (KBr) $v_{\max } 3168(\mathrm{~N}-\mathrm{H}), 1696(\mathrm{C}=\mathrm{O}) \mathrm{cm}^{-1}$; ${ }^{1} \mathrm{H}$ NMR $\left(500 \mathrm{MHz}, \mathrm{CDCl}_{3}\right) \delta: .89(\mathrm{~s}, 1 \mathrm{H}, \mathrm{NH}-1), 7.79$ (s, $\left.1 \mathrm{H}, \mathrm{H}-\mathrm{vinyl}\right)$, 7.68(m, 2H, H-3', 5'), 7.62(d, 1H, J=7.9 Hz H-4), 7.25 (m, 1H, H-6), 7.19 $\left(\mathrm{m}, 2 \mathrm{H}, \mathrm{H}-2^{\prime}, 6^{\prime}\right), 6.91(\mathrm{~m}, 2 \mathrm{H}, \mathrm{H}-5,7)$; ESI-MS: Observed $[\mathrm{M}+\mathrm{H}]^{+}=240$. Calculated for $\mathrm{C}_{15} \mathrm{H}_{10} \mathrm{FNO}=239$; Anal., found: $\mathrm{C}$, 75.31; $\mathrm{H}, 4.22 ; \mathrm{F}, 7.92$; N, 5.83; O, 6.70. Calculated: C, 75.30; H, 4.21; F, 7.94; N, 5.85; O, 6.69\%.

(E)-3-(3-Fluorobenzylidene) indolin-2-one $\left(a_{13}\right)$ : Yield: 70\%; mp164-65 ${ }^{\circ} \mathrm{C}$, ethanol; IR (KBr) $v_{\max } 3169(\mathrm{~N}-\mathrm{H}), 1719(\mathrm{C}=\mathrm{O}) \mathrm{cm}^{-1} ;{ }^{1} \mathrm{H}$ NMR (500 MHz, $\mathrm{CDCl}_{3}$ ) $\delta: .93$ (bs, $\left.1 \mathrm{H}, \mathrm{NH}-1\right), 7.78$ (s, 1H, H-2'), 7.60 $\left(\mathrm{d}, 1 \mathrm{H}, \mathrm{J}=7.8 \mathrm{~Hz}, \mathrm{H}\right.$ - vinyl), $7.46\left(\mathrm{~m}, 2 \mathrm{H}, \mathrm{H}-, 4^{\prime}\right), 7.37(\mathrm{~d}, 1 \mathrm{H}, \mathrm{J}=10 \mathrm{~Hz}$, H-'), 7.26 (m, 1H, H-6), 7.16 (m, 1H, H-5), 6.92 (t, 2H, J=7.7 Hz, H-5', 7); ESI-MS: Observed $[\mathrm{M}+\mathrm{H}]^{+}=240$. Calculated for $\mathrm{C}_{15} \mathrm{H}_{10} \mathrm{FNO}=239$; Anal., found: C, 75.32; H, 4.21; F, 7.93; N, 5.84; O, 6.68. Calculated: C, 75.30; H, 4.21; F, 7.94; N, 5.85; O, 6.69\%.

3-(2-Fluorobenzylidene)indolin-2-one $\left(\mathbf{a}_{14}\right)$ : Yield: $70 \%$; $\mathrm{mp}$ : 18.8-2 $1^{\circ} \mathrm{C}$, ethanol; ${ }^{1} \mathrm{H}$ NMR $\left(500 \mathrm{MHz}, \mathrm{CDCl}_{3}\right) \delta: .9$ (bs, $1 \mathrm{H}, \mathrm{J}=8.7$, NH-1 ), 7.84 (s, 1H, J=8.7; H-vinyl), 7.74 (t, 1H, H-3'), 7.45 (m, 2H, H-4, 6'), 7.24 (m, H-3', 4', 5'), 6.89 (m, 2H, H-5, 7).; ESI-MS: Observed $[\mathrm{M}+\mathrm{H}]^{+}=240$. Calculated for $\mathrm{C}_{15} \mathrm{H}_{10} \mathrm{FNO}=239$; Anal., found: $\mathrm{C}, 75.32$; $\mathrm{H}, 4.22$; F, 7.94; N, 5.86; O, 6.69. Calculated for $\mathrm{C}_{15} \mathrm{H}_{10} \mathrm{FNO}$ : C, 75.30; $\mathrm{H}, 4.21 ; \mathrm{F}, 7.94 ; \mathrm{N}, 5.85 ; \mathrm{O}, 6.69 \%$.

(E)-3-(4-Chlorobenzylidene) indolin-2-one $\left(\mathrm{a}_{15}\right)$ : Yield: 65\%; mp182-84 ${ }^{\circ} \mathrm{C}$, ethanol; IR $(\mathrm{KBr}) v_{\max } 3163(\mathrm{~N}-\mathrm{H}), 1719(\mathrm{C}=\mathrm{O}) \mathrm{cm}^{-1}$; ${ }^{1} \mathrm{H}$ NMR $\left(500 \mathrm{MHz}, \mathrm{CDCl}_{3}\right): \delta 7.77(\mathrm{~s}, 1 \mathrm{H}, \mathrm{NH}-1), 7.61(\mathrm{~m}, 3 \mathrm{H}, \mathrm{H}-2$ ', 6', 4), 7.48 (s, 1H, NH-1), 7.47 (m, 2H, H-3', 5'), 7.25 (m, 1H, H-6), 
6.89 (m, 2H, H-5, 7); ESI-MS: Observed $\left[\mathrm{M}+\mathrm{H}^{+}\right]=256,\left[\mathrm{M}+\mathrm{Na}^{+}\right]=278$. Calculated for $\mathrm{C}_{15} \mathrm{H}_{10} \mathrm{ClNO}=255$; Anal., found: $\mathrm{C}, 70.45 ; \mathrm{H}, 3.93 ; \mathrm{Cl}$, 13.85; N, 5.47; O, 6.24. Calculated for $\mathrm{C}_{15} \mathrm{H}_{10}$ ClNO: C, 70.46; $\mathrm{H}, 3.94$; $\mathrm{Cl}, 13.87 ; \mathrm{N}, 5.48 ; \mathrm{O}, 6.26 \%$.

(E)-3-(3-Chlorobenzylidene)indolin-2-one $\left(\mathrm{a}_{16}\right)$ : Yield: $21.5 \%$; mp: 66.4- $167.7^{\circ} \mathrm{C}$, ethanol; IR $(\mathrm{KBr}) v_{\max } 3185(\mathrm{~N}-\mathrm{H}), 1709(\mathrm{C}=\mathrm{O}) \mathrm{cm}$ ${ }_{1}^{1} ;{ }^{1} \mathrm{H}$ NMR $\left(500 \mathrm{MHz}, \mathrm{CDCl}_{3}\right): \delta 7.75$ (s, $1 \mathrm{H}, \mathrm{H}-8$ ), 7.66 (bs, $\left.1 \mathrm{H}, \mathrm{NH}-1\right)$, 7.65 (s, 1H, H-2'), 7.55 (m, 2H, H-4, 5'), 7.44(d, 2H, J=5.3, H-6', 4'), 7.26 (m, $1 \mathrm{H}, \mathrm{H}-6), 6.91(\mathrm{~m}, 2 \mathrm{H}, \mathrm{H}-5,7)$; ESI-MS: Observed $\left[\mathrm{M}+\mathrm{H}^{+}\right]=256$, $\left[\mathrm{M}+\mathrm{Na}^{+}\right]=278$. Calculated for $\mathrm{C}_{15} \mathrm{H}_{10} \mathrm{ClNO}=255$; Anal., found: $\mathrm{C}, 70.47$; $\mathrm{H}, 3.95 ; \mathrm{Cl}, 13.87 ; \mathrm{N}, 5.49 ; \mathrm{O}, 6.27$. Calculated: C, 70.46; H, 3.94; Cl, $13.87 ; \mathrm{N}, 5.48 ; \mathrm{O}, 6.26 \%$.

3-(2-Chlorobenzylidene)indolin-2-one $\left(\mathbf{a}_{17}\right)$ : Yield: $15 \%$; mp: 82$84^{\circ} \mathrm{C}$ (lit mp: $\mathrm{fZ}$ isomere $\left.=181^{\circ} \mathrm{C}\right)$ [25], ethanol; IR $(\mathrm{KBr}) v_{\max } 3192(\mathrm{~N}-$ $\mathrm{H}), 1718(\mathrm{C}=\mathrm{O}) \mathrm{cm}^{-1}$; ESI-MS: Observed $\left[\mathrm{M}+\mathrm{H}^{+}\right]=256,[\mathrm{M}+\mathrm{Na}]^{+}=278$. Calculated for $\mathrm{C}_{15} \mathrm{H}_{10} \mathrm{ClNO}=255$; Anal., found: $\mathrm{C}, 70.45 ; \mathrm{H}, 3.94 ; \mathrm{Cl}$, 13.87 ; N, 5.50; O, 6.26. Calculated: C, 70.46; H, 3.94; Cl, 13.87; N, 5.48; $\mathrm{O}, 6.26 \%$.

3-(4-Methylbenzylidene)indolin-2-one ( $\left.\mathbf{a}_{18}\right)$ : Yield: 67\%; mp: 89$191^{\circ} \mathrm{C}$, ethanol; IR $(\mathrm{KBr}) v_{\max } 3122(\mathrm{~N}-\mathrm{H}), 1682(\mathrm{C}=\mathrm{O}) \mathrm{cm}^{-1} ;{ }^{1} \mathrm{H}$ NMR (500 MHz, $\mathrm{CDCl}_{3}$ ): $\delta 9.5$ (s, 1H, NH-1), $7.78(\mathrm{~s}, 1 \mathrm{H}, \mathrm{H}-$ vinyl), $7.75(\mathrm{~d}$, $1 \mathrm{H}, \mathrm{J}=7.7 \mathrm{~Hz}, \mathrm{H}-4), 7.64\left(\mathrm{~d}, 2 \mathrm{H}, \mathrm{J}=7.9 \mathrm{~Hz}, \mathrm{H}-2^{\prime}, 6^{\prime}\right), 7.32\left(\mathrm{~m}, 2 \mathrm{H}, \mathrm{H}-3^{\prime}\right.$, 5'), $7.25(\mathrm{~m}, 1 \mathrm{H}, \mathrm{H}-6), 7(\mathrm{~d}, 1 \mathrm{H}, \mathrm{J}=7.7 \mathrm{~Hz}, \mathrm{H}-7), 6.92(\mathrm{t}, 1 \mathrm{H}, \mathrm{J}=7.4 \mathrm{~Hz}$, $\mathrm{H}-5), 2.48\left(\mathrm{~s}, 3 \mathrm{H}, \mathrm{CH}_{3}\right)$; ESI-MS: Observed $[\mathrm{M}+\mathrm{H}]^{+}=236$. Calculated for $\mathrm{C}_{16} \mathrm{H}_{13} \mathrm{NO}=235$; Anal., found: $\mathrm{C}, 81.67 ; \mathrm{H}, 5.55 ; \mathrm{N}, 5.94 ; \mathrm{O}, 6.81$. Calculated: C, $81.68 ; \mathrm{H}, 5.57 ; \mathrm{N}, 5.95 ; \mathrm{O}, 6.80 \%$.

3-(4-Bromobenzylidene)indolin-2-one $\left(\mathbf{a}_{19}\right)$ : Yield: $22 \%$; $\mathrm{mp}$ : 95-197 ${ }^{\circ} \mathrm{C}$ (lit $\left.\mathrm{mp}=191-92\right)$ [29], ethanol; IR (KBr) v $3188(\mathrm{~N}-\mathrm{H})$, $1713(\mathrm{C}=\mathrm{O}) \mathrm{cm}^{-1}$; ESI-MS: Observed $[\mathrm{M}+\mathrm{H}]^{+}=300$, 302. Calculated for $\mathrm{C}_{15} \mathrm{H}_{10} \mathrm{BrNO}=299$; Anal., found: $\mathrm{C}, 60.00 ; \mathrm{H}, 3.35 ; \mathrm{Br}, 26.60 ; \mathrm{N}, 4.66 ; \mathrm{O}$, 5.34. Calculated for $\mathrm{C}_{15} \mathrm{H}_{10} \mathrm{BrNO}$ : $\mathrm{C}, 60.02 ; \mathrm{H}, 3.36$; $\mathrm{Br}, 26.62 ; \mathrm{N}, 4.67$; $\mathrm{O}, 5.33 \%$.

3-(3-Bromobenzylidene)indolin-2-one $\left(\mathbf{a}_{20}\right)$ : Yield: $23 \%$; mp: $63-$ $164^{\circ} \mathrm{C}$, ethanol; IR $(\mathrm{KBr}) v_{\max } 3179(\mathrm{~N}-\mathrm{H}), 1699(\mathrm{C}=\mathrm{O}) \mathrm{cm}^{-1}$; ESI-MS: Observed $\left(\mathrm{M}+\mathrm{H}^{+}\right)=300$, 302 Calculated for $\mathrm{C}_{15} \mathrm{H}_{10} \mathrm{BrNO}=299$; Anal., found: $\mathrm{C}, 60.04 ; \mathrm{H}, 3.35 ; \mathrm{Br}, 26.61 ; \mathrm{N}, 4.68 ; \mathrm{O}, 5.32$. Calculated: $\mathrm{C}$, $60.02 ; \mathrm{H}, 3.36 ; \mathrm{Br}, 26.62 ; \mathrm{N}, 4.67 ; \mathrm{O}, 5.33 \%$.

3-(2-Bromobenzylidene)indolin-2-one $\left(\mathbf{a}_{21}\right)$ : Yield: $36 \%$; $\mathrm{mp}$ : 84.7-86. ${ }^{\circ} \mathrm{C}$, ethanol; IR (KBr) $v_{\max } 3124(\mathrm{~N}-\mathrm{H}), 1709(\mathrm{C}=\mathrm{O}) \mathrm{cm}^{-1}$; ESI-MS: Observed $[\mathrm{M}+\mathrm{H}]^{+}=300,302$ Calculated for $\mathrm{C}_{15} \mathrm{H}_{10} \mathrm{BrNO}=299$; Anal., found: C, 60.03; H, 3.34; Br, 26.59; N, 4.69; O, 5.33. Calculated: C, $60.02 ; \mathrm{H}, 3.36 ; \mathrm{Br}, 26.62 ; \mathrm{N}, 4.67 ; \mathrm{O}, 5.33 \%$.

(E/Z)-3-((5-(4-Fluorophenyl)pyridin-3-yl)methylene)indolin-2one $\left(\mathbf{a}_{22}\right)$ : Yield: $85 \%$; mp: $04-206.9^{\circ} \mathrm{C}$ (dec.), ethanol; IR (KBr) $v_{\text {max }} 3160$ $(\mathrm{N}-\mathrm{H}), 1720(\mathrm{C}=\mathrm{O}), 1689,1607 \mathrm{~cm}^{-1} ;{ }^{1} \mathrm{H}$ NMR $\left(250 \mathrm{MHz}, \mathrm{DMSO}-\mathrm{d}_{6}\right)$ $\delta 10.70(\mathrm{~s}, 1 \mathrm{H}, \mathrm{NH}), 9.23$ (t, 1H, J=2.0 Hz, H-2'), 9.15 (d, 1H, J=1.8 Hz, H-6'), 8.9 (m, 1H, H-4'), 7.91 (s, 1H, H-vinyl), $7.84(\mathrm{~m}), 7.72(\mathrm{t}, 1 \mathrm{H}$, $\mathrm{J}=7.5 \mathrm{~Hz}, \mathrm{H}-4), 7.39$ (m), $7.26(\mathrm{t}, 1 \mathrm{H}, \mathrm{J}=7.5 \mathrm{~Hz}, \mathrm{H}-5), 7.05$ (t, 1H, J=7.5 $\mathrm{Hz}, \mathrm{H}-6), 6.87$ (m, 1H, H-7), mixture of $\mathrm{Z}$ and $\mathrm{E}$ isomers; ${ }^{13} \mathrm{C}-\mathrm{NMR}$ $\left(62.9 \mathrm{MHz}, \mathrm{DMSO}-\mathrm{d}_{6}\right) \delta 115.9,116.2,120.2,120.7,121.3,122.1,124.3$, $128.9,129,129.1,129.6,129.8,130.6,130.7,131.8,132.4,132.7,132.8$, 133.3, 133.7, 134.3, 135.6, 141.1, 143.2, 147.9, 148, 148.1, 150.9, 160.5, 164.4, 167, 168.1; ESI-MS: Observed $[\mathrm{M}+\mathrm{H}]^{+}=317$. Calculated for $\mathrm{C}_{20} \mathrm{H}_{13} \mathrm{FN}_{2} \mathrm{O}=316.3$. Anal., found: $\mathrm{C}, 75.96 ; \mathrm{H}, 4.15 ; \mathrm{F}, 6.03 ; \mathrm{N}, 8.84 ; \mathrm{O}$, 5.05. Calculated: C, 75.94; H, 4.14; F, 6.01; N, 8.86; O, 5.06\%.

(E/Z)-3-((E)-3-Phenylallylidene)indolin-2-one $\left(\mathrm{a}_{23}\right)$ : Yield: 54\%; mp: $23.7-26.7^{\circ} \mathrm{C}$ (dec.), ethanol; IR (KBr) $v_{\max } 3167(\mathrm{~N}-\mathrm{H}), 1710(\mathrm{C}=\mathrm{O})$ $\mathrm{cm}^{-1}$; ${ }^{1} \mathrm{H}$ NMR $\left(500 \mathrm{MHz}, \mathrm{CDCl}_{3}\right) \delta 7.76(\mathrm{~d}, 1 \mathrm{H}, \mathrm{NH}), 9.23(\mathrm{t}, 1 \mathrm{H}, \mathrm{J}=2$
Hz, H-2'), 9.15 (d, 1H, J=1.8 Hz, H-'), 8.9 (m, 1H, H-4'), 7.91 (s, 1H, H-vinyl), 7.84 (m), 7.72 (t, 1H, J=7.5 Hz, H-4), 7.39 (m), 7.26 (t, 1H, $\mathrm{J}=7.5, \mathrm{H}-5), 7.05$ (t, 1H, J=7.5 Hz, H-6), 6.87 (m, 1H, H-7); ESI-MS: Observed $[\mathrm{M}+\mathrm{H}]^{+}=248$. Calculated for $\mathrm{C}_{17} \mathrm{H}_{13} \mathrm{NO}=247$. Anal., found: C, $82.55 ; \mathrm{H}, 5.30 ; \mathrm{N}, 5.65 ; \mathrm{O}, 6.46$. Calculated: C, 82.57; H, 5.30; N, 5.66; $\mathrm{O}, 6.47 \%$.

(Z)-3-(3-Phenoxybenzylidene)indolin-2-one $\left(\mathrm{a}_{24}\right)$ : Yield: $10 \%$; mp140-41.5 ${ }^{\circ} \mathrm{C}$ (dec.), ethanol; IR (KBr) $v_{\max } 3135(\mathrm{~N}-\mathrm{H}), 1704(\mathrm{C}=\mathrm{O})$ $\mathrm{cm}^{-1}$; ${ }^{1} \mathrm{H}$ NMR $\left(500 \mathrm{MHz}, \mathrm{CDCl}_{3}\right): \delta 7.77(\mathrm{~s}, 1 \mathrm{H}, \mathrm{NH}), 9.23(\mathrm{t}, 1 \mathrm{H}$, J=2 Hz; H-2'), 9.15 (d, 1H, J=1.8 Hz; H-6'), 8.9 (m, 1H, H-4'), 7.91 (s, $1 \mathrm{H}, \mathrm{H}$-vinyl), $7.84(\mathrm{~m}), 7.72(\mathrm{t}, 1 \mathrm{H}, \mathrm{J}=7.5 \mathrm{~Hz} ; \mathrm{H}-4), 7.39(\mathrm{~m}), 7.26(\mathrm{t}$, $1 \mathrm{H}, \mathrm{J}=7.5, \mathrm{H}-5), 7.05$ (t, 1H, J=7.5, H-6), 6.87 (m, 1H, H-7); ESI-MS: Observed $[\mathrm{M}+\mathrm{H}]^{+}=314$. Calculated for $\mathrm{C}_{21} \mathrm{H}_{15} \mathrm{NO}_{2}=313$. Anal., found: $\mathrm{C}, 80.48 ; \mathrm{H}, 4.81 ; \mathrm{N}, 4.48 ; \mathrm{O}, 10.20$. Calculated for $\mathrm{C}_{21} \mathrm{H}_{15} \mathrm{NO}_{2}: \mathrm{C}, 80.49$; $\mathrm{H}, 4.82 ; \mathrm{N}, 4.47 ; \mathrm{O}, 10.21 \%$.

(E)-N-(4-((2-Oxoindolin-3-ylidene) methyl)phenyl)acetamide $\left(\mathbf{a}_{25}\right)$ : Yield: $17 \%$; mp: $77-90^{\circ} \mathrm{C}\left(\mathrm{dec}\right.$.); ethanol; IR $(\mathrm{KBr}) v_{\max } 3285(\mathrm{~N}-$ $\mathrm{H}), 3071$ ( NH of acetamide), $1710(\mathrm{C}=\mathrm{O}), 1658(\mathrm{C}=\mathrm{O}$ of acetamide), $1592 \mathrm{~cm}^{-1} ;{ }^{1} \mathrm{H}$ NMR (500 MHz, DMSO-d $\left.{ }_{6}\right) \delta: 10.56$ (s, $1 \mathrm{H}, \mathrm{NH}-1$ ), 10.22 (s, $1 \mathrm{H}, \mathrm{NH}$ of acetamide), $7.74\left(\mathrm{~d}, 2 \mathrm{H}, \mathrm{J}=8.5 \mathrm{~Hz}, \mathrm{H}-2^{\prime}, 6^{\prime}\right), 7.69$ (d, 2H, J=8.5 Hz, H-3', 5'), $7.65(\mathrm{~d}, 1 \mathrm{H}, \mathrm{J}=7.6 \mathrm{~Hz}, \mathrm{H}-4), 7.56(\mathrm{~s}, 1 \mathrm{H}$, H-vinyl), 7.22 (t, 1H, J=7.6 Hz, H-6), 6.88 (m, 2H, H-5, 7), 2.10 (s, $\left.3 \mathrm{H}, \mathrm{NHCOCH}_{3}-^{-}\right)$; ESI-MS: Observed $[\mathrm{M}+\mathrm{H}]^{+}=278$. Calculated for $\mathrm{C}_{17} \mathrm{H}_{14} \mathrm{~N}_{2} \mathrm{O}_{2}=278$. Anal., found: $\mathrm{C}, 73.35 ; \mathrm{H}, 5.06 ; \mathrm{N}, 10.05 ; \mathrm{O}, 11.49$. Calculated: C, 73.37; H, 5.07; N, 10.07; O, 11.50\%.

N-(2-Fluoro-4-((2-oxoindolin-3-ylidene)methyl)phenyl) acetamide $\left(\mathbf{a}_{26}\right)$ : Yield: $15 \%$; mp: $49-252^{\circ} \mathrm{C}(\mathrm{dec}$.$) , ethanol; IR (\mathrm{KBr})$ $v_{\max } 3185(\mathrm{NH}), 3175(\mathrm{NH}$ of acetamide), $1710(\mathrm{C}=\mathrm{O}), 1660(\mathrm{C}=\mathrm{O}$ of acetamide), $1613 \mathrm{~cm}^{-1} ;{ }^{1} \mathrm{H}$ NMR $\left(250 \mathrm{MHz}, \mathrm{DMSO}-\mathrm{d}_{6}\right) \delta 10.69(\mathrm{~s}$, $1 \mathrm{H}, \mathrm{NH}-1), 10(\mathrm{~s}, 1 \mathrm{H}, \mathrm{NH}$ of acetamide), $8.14(\mathrm{dt}, 1 \mathrm{H}, \mathrm{J}=8.5,1.8 \mathrm{~Hz}$; H-6), 7.72(m), 7.23 (dd, 2H, J=15, $7.5 \mathrm{~Hz}, \mathrm{H}-5^{\prime}, 6$ '), 6.9 (m), 2.14(s, $\left.3 \mathrm{H}, \mathrm{NHCOCH}_{3}-4^{\prime}\right)$, mixture of $\mathrm{Z}$ and $\mathrm{E}$ isomers; ${ }^{13} \mathrm{C}-\mathrm{NMR}(62.9 \mathrm{MHz}$, DMSO-d $) \delta 109.3,110.1,116.2,116.5,117.5,117.8,118.6,119.6,120.6$, $121.1,121.2,122.3,123,124,125.6,126.3,127.4,127.5,127.7,128.9$, $129.5,129.7,130.2,130.4,130.5,130.7,134.2,140.6,142.9,150.5,154.4$, 167.2, 168.5, 169, 169.1; ESI-MS: Observed $[\mathrm{M}+\mathrm{H}]^{+}=297$. Calculated for $\mathrm{C}_{17} \mathrm{H}_{13} \mathrm{FN}_{2} \mathrm{O}_{2}=296$ Anal., found: $\mathrm{C}, 68.93 ; \mathrm{H}, 4.41 ; \mathrm{F}, 6.43 ; \mathrm{N}, 9.47 ; \mathrm{O}$, 10.82. Calculated: C, 68.91; H, 4.42; F, 6.41; N, 9.45; O, 10.80\%.

N-(2-Chloro-4-((2-oxoindolin-3-ylidene)methyl)phenyl) acetamide $\left(\mathrm{a}_{27}\right)$ : Yield: $56 \%$; mp: $20-228^{\circ} \mathrm{C}(\mathrm{dec}$.), ethanol; IR $(\mathrm{KBr})$ $v_{\max } 3184(\mathrm{~N}-\mathrm{H}), 3082(\mathrm{NH}$ of acetamide), $1702(\mathrm{C}=\mathrm{O}), 1662(\mathrm{C}=\mathrm{O}$ of acetamide), $1611 \mathrm{~cm}^{-1} ;{ }^{1} \mathrm{H}$ NMR $\left(250 \mathrm{MHz}, \mathrm{DMSO}-\mathrm{d}_{6}\right) \delta 10.65(\mathrm{~s}, 1 \mathrm{H}$, $\mathrm{NH}-1), 9.66$ (s, 1H, NH of acetamide), 7 (m), 2.15 (s, 3H, $\mathrm{NHCOCH}_{3}$ $\left.-4^{\prime}\right)$, mixture of $\mathrm{Z}$ and $\mathrm{E}$ isomers; ${ }^{13} \mathrm{C}-\mathrm{NMR}\left(62.9 \mathrm{MHz}, \mathrm{DMSO}-\mathrm{d}_{6}\right) \delta^{3}$ 23.5, 23.6, 109.4, 110.2, 119.8, 120.6, 121.1, 121.2, 122.2, 124, 124.4, $124.6,125,125.4,126.8,127.8,128.2,129.1,130.2,130.3,131.2,131.5$, 131.7, 132.1, 133.8, 134.6, 136, 136.5, 140.7, 142.9, 167.1, 168.5, 169; ESI-MS: Observed $[\mathrm{M}+\mathrm{H}]^{+}=313$. Calculated for $\mathrm{C}_{17} \mathrm{H}_{13} \mathrm{ClN}_{2} \mathrm{O}_{2}=312$; Anal., found: $\mathrm{C}, 65.31 ; \mathrm{H}, 4.2 ; \mathrm{Cl}, 11.36 ; \mathrm{N}, 8.95 ; \mathrm{O}, 10.21$. Calculated for $\mathrm{C}_{17} \mathrm{H}_{13} \mathrm{ClN}_{2} \mathrm{O}_{2}$ : C, 65.29; $\mathrm{H}, 4.19 ; \mathrm{Cl}, 11.34 ; \mathrm{N}, 8.96 ; \mathrm{O}, 10.23 \%$.

(Z)-3-(Thiophen-2-ylmethylene)indolin-2-one $\left(\mathrm{a}_{28}\right)$ : Yield: $54 \%$; mp: $08-209^{\circ} \mathrm{C}$ (dec.), ethanol; IR (KBr) $v_{\max } 3171(\mathrm{~N}-\mathrm{H}), 1677(\mathrm{C}=\mathrm{O})$ $\mathrm{cm}^{-1} ;{ }^{1} \mathrm{H}$ NMR $\left(500 \mathrm{MHz}, \mathrm{CDCl}_{3}\right): \delta 8.14(\mathrm{~s}, 1 \mathrm{H}, \mathrm{NH}), 7.89(\mathrm{~d}, 1 \mathrm{H}, \mathrm{J}=3.6$ Hz; H-3'), 7.78 (s, 1H, H-vinyl), 7.7 (d, 1H, J=5.1 Hz, H-5'), 7.56 (d, $1 \mathrm{H}, \mathrm{J}=7.6 \mathrm{~Hz} \mathrm{H}-4), 7.27$ (t, 1H, J=7.6 Hz, H-4'), $7.22(\mathrm{t}, 1 \mathrm{H}, \mathrm{J}=4.4 \mathrm{~Hz}$; H-6), 7.09 (t, 1H, J=7.7 Hz, H-5), 6.94 (d, 1H, J=7.7Hz, H-7); ESI-MS: Observed $[\mathrm{M}+\mathrm{H}]^{+}=228$. Calculated for $\mathrm{C}_{13} \mathrm{H}_{9} \mathrm{NOS}=227$. Anal., found: C, 68.71; H, 3.98; N, 6.17; O, 7.03; S, 14.10. Calculated for $\mathrm{C}_{13} \mathrm{H}_{9} \mathrm{NOS}$ : C, 68.70; H, 3.99; N, 6.16; O, 7.04; S, 14.11\%. 
(E/Z)-3-(Furan-2-ylmethylene)indolin-2-one $\left(\mathbf{a}_{29}\right)$ : Yield: $22 \%$; mp: 83.9-85.09 ${ }^{\circ} \mathrm{C}$ (dec.), ethanol; IR (KBr) $v_{\max } 3131(\mathrm{~N}-\mathrm{H}), 1697$ $(\mathrm{C}=\mathrm{O}) \mathrm{cm}^{-1} ;{ }^{1} \mathrm{H}$ NMR $\left(500 \mathrm{MHz}, \mathrm{CDCl}_{3}\right) \delta: 8.49(\mathrm{~d}, 1 \mathrm{H}, \mathrm{J}=7.76, \mathrm{H}-4)$, $8.08(\mathrm{~m}, 1 \mathrm{H}, \mathrm{NH}-1), 7.8$ (d, $\left.1 \mathrm{H}, \mathrm{J}=1.8 \mathrm{~Hz} ; \mathrm{H}-5^{\prime}\right), 7.48$ (s, $1 \mathrm{H}, \mathrm{H}$-vinyl), $7.28\left(\mathrm{~m}, 2 \mathrm{H}, \mathrm{H}-6,3^{\prime}\right), 7.1(\mathrm{t}, 1 \mathrm{H}, \mathrm{J}=6.8 \mathrm{~Hz}, \mathrm{H}-5), 6.95(\mathrm{~d}, 1 \mathrm{H}, \mathrm{J}=3.4 \mathrm{~Hz}$, $\mathrm{H}-5), 6.91(\mathrm{~d}, 1 \mathrm{H}, \mathrm{J}=7.8 \mathrm{~Hz}, \mathrm{H}-7), 6.65$ (dd, $\left.1 \mathrm{H}, \mathrm{J}=2.6,1.8 \mathrm{~Hz}, \mathrm{H}-4^{\prime}\right)$; ESI-MS: Observed $[\mathrm{M}+\mathrm{H}]^{+}=212$. Calculated for $\mathrm{C}_{13} \mathrm{H}_{9} \mathrm{NO}_{2}=211$. Anal., found: $\mathrm{C}, 73.91 ; \mathrm{H}, 4.28 ; \mathrm{N}, 6.64 ; \mathrm{O}, 15.16$. Calculated: $\mathrm{C}, 73.92 ; \mathrm{H}, 4.29$; $\mathrm{N}, 6.63 ; \mathrm{O}, 15.15 \%$.

3-(4-((4-methylpiperazin-1-yl)methyl)benzylidene)indolin2-one $\left(\mathbf{a}_{30}\right)$ : Yield: $38 \%$; mp: $64-269^{\circ} \mathrm{C}$ (dec.), ethanol; ${ }^{1} \mathrm{H}$ NMR $(500$ MHz, DMSO-d $\left.{ }_{6}\right) \delta 10.58$ (s, 1H, NH-1), 7.66 (d, 2H, J=8 Hz, H-2', 6'), 7.59 (s, $1 \mathrm{H}, \mathrm{H}$ - vinyl), 7.56 (d, J=8 Hz, $1 \mathrm{H}, \mathrm{H}-4), 7.43$ (d, 2H, J=8, H-3', 5'), $7.21(\mathrm{t}, 1 \mathrm{H}, \mathrm{J}=7.5 \mathrm{~Hz}, \mathrm{H}-6), 6.85(\mathrm{~m}, 2 \mathrm{H}, \mathrm{H}-5,7), 3.52\left(\mathrm{~s}, 2 \mathrm{H}, \mathrm{CH}_{2}\right)$, 2.37(m, 8H, Piperazine $\left.\mathrm{CH}_{2}\right), 2.16\left(\mathrm{~s}, 3 \mathrm{H}, \mathrm{CH}_{3}\right) ;{ }^{13} \mathrm{C}-\mathrm{NMR}(62.9 \mathrm{MHz}$, DMSO-d $\left.\mathrm{d}_{6}\right) \delta 45.2,52.1,54.3,61.5,110.1,120.8,121.1,122.3,127.1$, $128.5,129,129.2,130,131.8,132.9,135.7,140.2,142.8,164.6,168.6$; ESI-MS: Observed $[\mathrm{M}+\mathrm{H}]^{+}=334$. Calculated for $\mathrm{C}_{21} \mathrm{H}_{23} \mathrm{~N}_{3} \mathrm{O}=333.43$; Anal., found: C, 75.70; H, 6.93; N, 12.58; O, 4.78. Calculated: C, 75.65; $\mathrm{H}, 6.95 ; \mathrm{N}, 12.60 ; \mathrm{O}, 4.80 \%$.

(E/Z)-5-Chloro-3-(4'-methybenzylidene)indolin-2-one $\quad\left(a_{31}\right)$ : Yield: $74 \%$; $\mathrm{mp}: 12-16^{\circ} \mathrm{C}$ (dec.) (lit $\mathrm{mp}=220-223$ ) [24], ethanol; ESI-MS: Observed $[\mathrm{M}+\mathrm{H}]^{+}=270, \quad[\mathrm{M}+\mathrm{Na}]^{+}=292$. Calculated for $\mathrm{C}_{16} \mathrm{H}_{12} \mathrm{ClNO}=269$; Anal., found: $\mathrm{C}, 71.26 ; \mathrm{H}, 4.49 ; \mathrm{Cl}, 13.15 ; \mathrm{N}, 5.2 ; \mathrm{O}$, 5.94. Calculated: $71.25 ; \mathrm{H}, 4.48 ; \mathrm{Cl}, 13.14 ; \mathrm{N}, 5.19 ; \mathrm{O}, 5.93 \%$.

(E/Z)-3-(4-hydroxybenzylidene)-5-chloroindolin-2-one $\quad\left(a_{33}\right)$ : Yield: $74 \%$; mp: $77-278^{\circ} \mathrm{C}$ (dec.), ethanol; IR (KBr) $v_{\max } 3282(\mathrm{~N}-\mathrm{H})$, $1674(\mathrm{C}=\mathrm{O}) \mathrm{cm}^{-1}$; ESI-MS: Observed $[\mathrm{M}+\mathrm{H}]^{+}=272,[\mathrm{M}+\mathrm{Na}]^{+}=294$. Calculated for $\mathrm{C}_{15} \mathrm{H}_{10} \mathrm{ClN}_{2} \mathrm{O}=271$; Anal., found: $\mathrm{C}, 66.30 ; \mathrm{H}, 3.72 ; \mathrm{Cl}$, 13.02; N, 5.14; O, 11.76. Calculated: C, 66.31; H, 3.71; Cl, 13.05; N, 5.16; $\mathrm{O}, 11.78 \%$.

(E/Z)-5-chloroindolin-2-one $\quad\left(\mathbf{a}_{33}\right)$ : Yield: 74\%; $\mathrm{mp}$ : 77$278^{\circ} \mathrm{C}$ (dec.), ethanol; IR ( $\left.\mathrm{KBr}\right) v_{\max } 3282(\mathrm{~N}-\mathrm{H}), 1674(\mathrm{C}=\mathrm{O}) \mathrm{cm}$ 1; ESI-MS: Observed $[\mathrm{M}+\mathrm{H}]^{+}=272,[\mathrm{M}+\mathrm{Na}]^{+}=294$. Calculated for $\mathrm{C}_{15} \mathrm{H}_{10} \mathrm{ClN}_{2} \mathrm{O}=271$; Anal., found: $\mathrm{C}, 66.30 ; \mathrm{H}, 3.72 ; \mathrm{Cl}, 13.02 ; \mathrm{N}, 5.14$; O, 11.76. Calculated: C, 66.31; H, 3.71; Cl, 13.05; N, 5.16; O, 11.78\%.

3-(4-Bromobenzylidene)-5-chloroindolin-2-one $\quad\left(a_{34}\right)$ Yield: 30\%; mp: $42-47.7^{\circ} \mathrm{C}$ (dec.), ethanol; ESI-MS: Observed $[\mathrm{M}+\mathrm{H}]^{+}=335$, $[\mathrm{M}+\mathrm{Na}]^{+}=357$. Calculated for $\mathrm{C}_{16} \mathrm{H}_{9} \mathrm{ClN}_{2} \mathrm{O}=334$; Anal., found: $\mathrm{C}, 53.81$; $\mathrm{H}, 2.70 ; \mathrm{Br}, 23.86 ; \mathrm{Cl}, 10.62 ; \mathrm{N}, 4.18 ; \mathrm{O}, 4.77$. Calculated: C, 53.84; H, $2.71 ; \mathrm{Br}, 23.88 ; \mathrm{Cl}, 10.60 ; \mathrm{N}, 4.19 ; \mathrm{O}, 4.78 \%$.

3-(4-Bromobenzylidene)-5-methylindolin-2-one $\left(a_{35}\right)$ : Yield: 51\%; mp: $18-20.1^{\circ} \mathrm{C}$ (dec.), ethanol; ESI-MS: Observed $[\mathrm{M}+\mathrm{H}]^{+}=313$, $[\mathrm{M}+\mathrm{Na}]^{+}=335$. Calculated for $\mathrm{C}_{16} \mathrm{H}_{12} \mathrm{BrNO}=312$; Anal., found: $\mathrm{C}, 61.15$; $\mathrm{H}, 3.83 ; \mathrm{Br}, 25.41 ; \mathrm{N}, 4.45 ; \mathrm{O}, 5.07$. Calculated: $\mathrm{C}, 61.17 ; \mathrm{H}, 3.85 ; \mathrm{Br}$, 25.43; N, 4.46; O, 5.09\%.

4-((5-Bromo-2-oxoindolin-3-ylidene)methyl)benzonitrile $\left(a_{36}\right)$ : Yield: $58 \%$; mp: $67-272.5^{\circ} \mathrm{C}$ (dec.), ethanol; IR (KBr) $v_{\text {max }} 3195(\mathrm{NH})$, 2246 (nitrile), $1712(\mathrm{C}=\mathrm{O}), 1613 \mathrm{~cm}^{-1}$; ${ }^{1} \mathrm{H}$ NMR $\left(250 \mathrm{MHz}, \mathrm{DMSO}-\mathrm{d}_{6}\right)$ $\delta 10.86$ (s, 1H, NH), 8.4 (d, 2H , J=8.25 Hz, H-3', 5'), 7.9 (m), 7.71 (s, $1 \mathrm{H}, \mathrm{H}$ - vinyl), $7.4(\mathrm{~m}), 6.83$ (dd, $\left.2 \mathrm{H}, \mathrm{J}=15 \mathrm{~Hz}, 8.25 ; \mathrm{H}-2{ }^{\prime}, 6^{\prime}\right)$, mixture of $\mathrm{Z}$ and $\mathrm{E}$ isomers; ${ }^{13} \mathrm{C}$-NMR (62.9 MHz, DMSO- $\mathrm{d}_{6}$ ) $\delta 116.2,116.7$, $116.9,117.5,117.9,123.2,123.4,127.1,127.9,129.5,131.2,133.1,133.3$, 134.6, 136.6, 136.8, 137.3, 137.8, 140, 140.7, 142.6, 143.6, 145, 147.1, 171.1, 172.4; ESI-MS: Observed $[\mathrm{M}+\mathrm{H}]^{+}=325,327,[\mathrm{M}+\mathrm{Na}]^{+}=347,349$. Calculated for $\mathrm{C}_{16} \mathrm{H}_{9} \mathrm{BrN}_{2} \mathrm{O}=325.16$; Anal., found: $\mathrm{C}$, 59.21; $\mathrm{H}, 2.78$; $\mathrm{Br}$, 24.59; N, 8.60; O, 4.91. Calculated for $\mathrm{C}_{16} \mathrm{H}_{9} \mathrm{BrN}_{2} \mathrm{O}: \mathrm{C}, 59.10 ; \mathrm{H}, 2.79$;
$\mathrm{Br}, 24.57 ; \mathrm{N}, 8.62 ; \mathrm{O}, 4.92 \%$.

3-(4-Hydroxybenzylidene)-5-bromoindolin-2-one $\left(a_{37}\right)$ : Yield: 75\%; mp: 91-92 ${ }^{\circ} \mathrm{C}$ (dec.), ethanol; IR (KBr) $v_{\max } 3293(\mathrm{NH}), 1679(\mathrm{C}=\mathrm{O})$ $\mathrm{cm}^{-1}$; ESI-MS: $[\mathrm{M}+\mathrm{H}]^{+}=316,318[\mathrm{M}+\mathrm{Na}]^{+}=338,340$. Calculated for $\mathrm{C}_{15} \mathrm{H}_{10} \mathrm{BrNO}_{2}=316$; Anal., found: $\mathrm{C}, 56.95 ; \mathrm{H}, 3.18 ; \mathrm{Br}, 25.23 ; \mathrm{N}, 4.42$; O, 10.11. Calculated: C, 56.99; H, 3.19; Br, 25.27; N, 4.43; O, 10.12\%.

3-(4-Bromobenzylidene)-5-bromoindolin-2-one $\left(\mathbf{a}_{38}\right)$ : Yield: $35 \%$; mp: $35-37^{\circ} \mathrm{C}$ (dec.), ethanol; ESI-MS: $[\mathrm{M}+\mathrm{H}]^{+}=379.5$, $[\mathrm{M}+\mathrm{Na}]^{+}=401.6$. Calculated for $\mathrm{C}_{15} \mathrm{H}_{9} \mathrm{Br}_{2} \mathrm{NO}=379$; Anal., found: $\mathrm{C}$, 47.51; H, 2.38; Br, 42.15; N, 3.72; O, 4.21. Calculated: C, 47.53; H, 2.39; $\mathrm{Br}, 42.16 ; \mathrm{N}, 3.70 ; \mathrm{O}, 4.22 \%$.

6-Chloro-3-(4-methylbenzylidene)-indolin-2-one $\left(a_{39}\right)$ : Yield: 37\%; mp: $214-18^{\circ} \mathrm{C}$, ethanol; ESI-MS: $[\mathrm{M}+\mathrm{H}]^{+}=271,[\mathrm{M}+\mathrm{Na}]^{+}=293$. Calculated for $\mathrm{C}_{16} \mathrm{H}_{12} \mathrm{ClNO}=270$; Anal., found: $\mathrm{C}, 71.26 ; \mathrm{H}, 4.47 ; \mathrm{Cl}$, 13.13; N, 5.18; O, 5.92. Calculated: C, 71.25; H, 4.48; Cl, 13.14; N, 5.19; $\mathrm{O}, 5.93 \%$.

4-((6-Chloro-2-oxoindolin-3-ylidene)methyl)benzonitrile $\left(a_{40}\right)$ : Yield: $54 \%$; mp: $06-310^{\circ} \mathrm{C}$ (dec.), ethanol; ESI-MS: $[\mathrm{M}+\mathrm{H}]^{+}=282$, $[\mathrm{M}+\mathrm{Na}]^{+}=304$. Calculated for $\mathrm{C}_{16} \mathrm{H}_{9} \mathrm{ClN}_{2} \mathrm{O}=281$; Anal., found: $\mathrm{C}, 68.43$; $\mathrm{H}, 3.22 ; \mathrm{Cl}, 12.60 ; \mathrm{N}, 9.96 ; \mathrm{O}, 5.71$. Calculated: C, 68.46; H, 3.23; Cl, $12.63 ; \mathrm{N}, 9.98 ; \mathrm{O}, 5.70 \%$.

3-(4-Hydroxybenzylidene)-6-chloroindolin-2-one $\left(a_{41}\right)$ : Yield: 10\%; mp: $65-72^{\circ} \mathrm{C}$ (dec.), ethanol; IR (KBr) $v_{\max } 3164(\mathrm{NH}), 1692$ $(\mathrm{C}=\mathrm{O}) \mathrm{cm}^{-1}$; ESI-MS: $[\mathrm{M}+\mathrm{H}]^{+}=271.9,[\mathrm{M}+\mathrm{Na}]^{+}=293.8$. Calculated for $\mathrm{C}_{15} \mathrm{H}_{10} \mathrm{ClNO}_{2}=271$; Anal., found: $\mathrm{C}, 66.30 ; \mathrm{H}, 3.70 ; \mathrm{Cl}, 13.03 ; \mathrm{N}, 5.15$; O, 11.77. Calculated: C, 66.31; H, 3.71; Cl, 13.05; N, 5.16; O, 11.78\%.

3-(4-Bromobenzylidene)-6-chloroindolin-2-one $\quad\left(a_{42}\right): \quad$ Yield: 84\%; mp: $80-95^{\circ} \mathrm{C}$ (dec.), ethanol; ESI-MS: $[\mathrm{M}+\mathrm{H}]^{+2}=335,337$, $[\mathrm{M}+\mathrm{Na}]^{+}=357,359$. Calculated for $\mathrm{C}_{15} \mathrm{H}_{9} \mathrm{BrClNO}=336$; Anal., found: C, 53.82; H, 2.70; Br, 23.87; Cl, 10.61, N, 4.18; O, 4.77. Calculated: C, $53.84 ; \mathrm{H}, 2.71 ; \mathrm{Br}, 23.88 ; \mathrm{Cl}, 10.60 ; \mathrm{N}, 4.19 ; \mathrm{O}, 4.78 \%$.

3-(Phenylimino)indolin-2-one $\left(\mathbf{b}_{1}\right)$ : Yield: $10 \% ; \mathrm{mp}: 22-24^{\circ} \mathrm{C}$ (dec.), ethanol; IR (KBr) $v_{\max } 3156(\mathrm{NH}), 1733(\mathrm{C}=\mathrm{O}) \mathrm{cm}^{-1}$; ESI-MS: $[\mathrm{M}+\mathrm{H}]^{+}=223,[\mathrm{M}+\mathrm{Na}]^{+}=244.9$. Calculated for $\mathrm{C}_{14} \mathrm{H}_{10} \mathrm{~N}_{2} \mathrm{O}=222$; Anal., found: $\mathrm{C}, 75.63 ; \mathrm{H}, 4.54 ; \mathrm{N}, 12.62 ; \mathrm{O}, 7.21$. Calculated: C, 75.66; H, 4.54; $\mathrm{N}, 12.60 ; \mathrm{O}, 7.20 \%$.

3-(4-Fluorophenylimino)indolin-2-one $\left(\mathbf{b}_{2}\right)$ : Yield: 10\%; mp: 20 $22^{\circ} \mathrm{C}$ (dec.); ethanol; IR ( $\left.\mathrm{KBr}\right) v_{\max } 3159(\mathrm{NH}), 1725(\mathrm{C}=\mathrm{O}) \mathrm{cm}^{-1}$; ESIMS: $[\mathrm{M}+\mathrm{H}]^{+}=240.9,[\mathrm{M}+\mathrm{Na}]^{+}=262.9$. Calculated for $\mathrm{C}_{14} \mathrm{H}_{9} \mathrm{FN}_{2} \mathrm{O}=222$; Anal., found: C, 69.97; H, 3.77; F, 7.90; N, 11.67; O, 6.67. Calculated: C, 69.99; H, 3.78; F, 7.91; N, 11.66; O, 6.66\%.

3-(Pyridin-4-ylimino)indolin-2-one $\quad\left(\mathbf{b}_{3}\right)$ : Yield: 10\%; $\mathrm{mp}$ : $70-275^{\circ} \mathrm{C}$ (dec.), ethanol; ESI-MS: Observed $[\mathrm{M}+\mathrm{H}]^{+}=223.9$, $[\mathrm{M}+\mathrm{Na}]^{+}=245.9$. Calculated for $\mathrm{C}_{13} \mathrm{H}_{9} \mathrm{~N}_{3} \mathrm{O}=223$; Anal., found: $\mathrm{C}, 69.93$; $\mathrm{H}, 4.05 ; \mathrm{N}, 18.80 ; \mathrm{O}, 7.16$. Calculated: $\mathrm{C}, 69.95 ; \mathrm{H}, 4.06 ; \mathrm{N}, 18.82 ; \mathrm{O}$, $7.17 \%$.

3-(Pyridin-4-ylimino) indolin-2-one $\left(\mathbf{b}_{4}\right)$ : Yield: 18\%; $\mathrm{mp}$ : 29.5-31 ${ }^{\circ} \mathrm{C}$ (dec.), ethanol; IR $(\mathrm{KBr}) v_{\max } 3052(\mathrm{NH}), 1710(\mathrm{C}=\mathrm{O}) \mathrm{cm}$ '; ESI-MS: Observed $[\mathrm{M}+\mathrm{H}]^{+}=223.9,[\mathrm{M}+\mathrm{Na}]^{+}=245.9$. Calculated for $\mathrm{C}_{13} \mathrm{H}_{9} \mathrm{~N}_{3} \mathrm{O}=223$; Anal., found: $\mathrm{C}, 69.92 ; \mathrm{H}, 4.05 ; \mathrm{N}, 18.80 ; \mathrm{O}, 7.16$. Calculated: C, 69.95; H, 4.04; N, 18.83; O, 7.15\%.

3-(4-Nitrophenylimino) indolin-2-one $\left(\mathbf{b}_{5}\right)$ : Yield: $10 \%$; $\mathrm{mp} 278$ $79.5^{\circ} \mathrm{C}$ (dec.), ethanol; IR (KBr) $v_{\max } 3283(\mathrm{NH}) 1739(\mathrm{C}=\mathrm{O}) \mathrm{cm}^{-1}$; ESI-MS: Observed $[\mathrm{M}+\mathrm{H}]^{+}=267.9,[\mathrm{M}+\mathrm{Na}]^{+}=289.9$. Calculated for $\mathrm{C}_{14} \mathrm{H}_{9} \mathrm{~N}_{3} \mathrm{O}_{3}=223$; Anal., found: $\mathrm{C}, 62.93 ; \mathrm{H}, 3.38 ; \mathrm{N}, 15.71 ; \mathrm{O}, 17.95$. Calculated: C, 62.92; H, 3.39; N, 15.72; O, 17.96\%. 
3-(3-Nitrophenylimino)indolin-2-one $\left(\mathbf{b}_{6}\right)$ : Yield: $10 \%$; $\mathrm{mp}$ : 28-228 ${ }^{\circ} \mathrm{C}$ (dec.), ethanol; IR $(\mathrm{KBr}) v_{\max } 3212(\mathrm{NH}) 1717(\mathrm{C}=\mathrm{O}) \mathrm{cm}^{-1}$; ESI-MS: Observed $[\mathrm{M}+\mathrm{H}]^{+}=267.9,[\mathrm{M}+\mathrm{Na}]^{+}=289.9$. Calculated for $\mathrm{C}_{14} \mathrm{H}_{9} \mathrm{~N}_{3} \mathrm{O}_{3}=223$; Anal., found: $\mathrm{C}, 62.91 ; \mathrm{H}, 3.37 ; \mathrm{N}, 15.73 ; \mathrm{O}, 17.97$. Calculated: C, 62.92; H, 3.39; N, 15.72; O, 17.96\%.

5-Nitro-3-(phenylimino)indolin-2-one $\left(\mathbf{b}_{7}\right)$ : Yield: $79 \%$; $\mathrm{mp}$ : 40-42 ${ }^{\circ} \mathrm{C}$ (dec.), ethanol; IR ( $\left.\mathrm{KBr}\right) v_{\max } 3253(\mathrm{NH}) 1737(\mathrm{C}=\mathrm{O}) \mathrm{cm}^{-1}$; ESI-MS: Observed $\left[\mathrm{M}+\mathrm{H}^{+}\right]=267.9,[\mathrm{M}+\mathrm{Na}]^{+}=289.9$. Calculated for $\mathrm{C}_{14} \mathrm{H}_{9} \mathrm{~N}_{3} \mathrm{O}_{3=} 223$; Anal., found: $\mathrm{C}, 62.91 ; \mathrm{H}, 3.37 ; \mathrm{N}, 15.73 ; \mathrm{O}, 17.97$. Calculated: C, C, 62.92; H, 3.39; N, 15.72; O, 17.96\%.

3-(4-Chlorophenylimino)-5-nitroindolin-2-one $\left(\mathbf{b}_{\mathbf{s}}\right)$ : Yield: 26\%; mp: $12-28^{\circ} \mathrm{C}$ (dec.), ethanol; IR (KBr) $v_{\max } 3095(\mathrm{NH}) 1733(\mathrm{C}=\mathrm{O}) \mathrm{cm}$ ; : ESI-MS: Observed $[\mathrm{M}+\mathrm{H}]^{+}=301.8,[\mathrm{M}+\mathrm{Na}]^{+}=323.8$. Calculated for $\mathrm{C}_{14} \mathrm{H}_{8} \mathrm{ClN}_{3} \mathrm{O}_{3}=300$; Anal., found: C, 55.73; H, 2.66; Cl, 11.77; N, 13.91; O, 15.90. Calculated: $\mathrm{C}, 55.74 ; \mathrm{H}, 2.67 ; \mathrm{Cl}, 11.75 ; \mathrm{N}, 13.93 ; \mathrm{O}, 15.91 \%$.

5-Nitro-3-(p-tolylimino)indolin-2-one $\quad\left(\mathbf{b}_{\mathbf{9}}\right): \quad$ Yield: $26 \%$; mp: $87-90^{\circ} \mathrm{C}$ (dec.), ethanol; ESI-MS: Observed $[\mathrm{M}+\mathrm{H}]^{+}=281.9$, $[\mathrm{M}+\mathrm{Na}]^{+}=303.9$. Calculated for $\mathrm{C}_{15} \mathrm{H}_{11} \mathrm{~N}_{3} \mathrm{O}_{3}=281$; Anal., found: $\mathrm{C}$, 64.03; H, 3.93; N, 14.93; O, 17.08. Calculated: C, 64.05; H, 3.94; N, $14.94 ; \mathrm{O}, 17.07 \%$.

3-(4-Hydroxyphenylimino)-5-nitroindolin-2-one $\left(b_{10}\right)$ : Yield: $70 \%$; mp: 52-59 ${ }^{\circ} \mathrm{C}$ (dec.), ethanol; IR ( $\left.\mathrm{KBr}\right) v_{\text {max }} 3380(\mathrm{OH}), 3095(\mathrm{NH})$, $1734(\mathrm{C}=\mathrm{O}) \mathrm{cm}^{-1}$; ESI-MS: Observed $[\mathrm{M}+\mathrm{H}]^{+}=283.9,[\mathrm{M}+\mathrm{Na}]^{+}=305.8$. Calculated for $\mathrm{C}_{14} \mathrm{H}_{9} \mathrm{~N}_{3} \mathrm{O}_{4}=283$; Anal., found: $\mathrm{C}, 59.37 ; \mathrm{H}, 3.20 ; \mathrm{N}$, 14.84; O, 22.59. Calculated: C, 59.37; H, 3.20; N, 14.84; O, 22.59\%.

N-(4-(5-Nitro-2-oxoindolin-3-ylideneamino)phenyl)acetamide $\left(\mathbf{b}_{11}\right)$ : Yield: $74 \%$; mp: $98-05^{\circ} \mathrm{C}$ (dec.), ethanol; IR (KBr) $v_{\max } 3195(\mathrm{NH})$, 2246 (nitrile), $1712(\mathrm{C}=\mathrm{O}), 1613 \mathrm{~cm}^{-1}$; ESI-MS: Observed $[\mathrm{M}+\mathrm{H}]^{+}=325$, $[\mathrm{M}+\mathrm{Na}]^{+}=347$. Calculated for $\mathrm{C}_{16} \mathrm{H}_{12} \mathrm{~N}_{4} \mathrm{O}_{4}=324$; Anal., found: $\mathrm{C}$, 59.25; H, 3.71; N, 17.27; O, 19.71. Calculated: C, 59.26; H, 3.73; N, 17.28; O, $19.73 \%$.

4-(5-Nitro-2-oxoindolin-3-ylideneamino)benzamide $\left(b_{12}\right)$ : Yield: 20\%; mp: $20-30^{\circ} \mathrm{C}$ (dec.), ethanol; ESI-MS: Observed $[\mathrm{M}+\mathrm{H}]^{+}=311$, $[\mathrm{M}+\mathrm{Na}]^{+}=333$. Calculated for $\mathrm{C}_{15} \mathrm{H}_{10} \mathrm{~N}_{4} \mathrm{O}_{4}=310$; Anal., found: $\mathrm{C}$, 58.05; $\mathrm{H}, 3.24 ; \mathrm{N}, 18.07$; O, 20.62. Calculated: $58.07 ; \mathrm{H}, 3.25 ; \mathrm{N}, 18.06$; O, $20.63 \%$.

5,7-Dichloro-3-(4-chlorophenylimino)indolin-2-one $\left(b_{13}\right)$ : Yield: $30 \%$; mp: $71.2-73^{\circ} \mathrm{C}$ (dec.), ethanol; IR (KBr) $v_{\max } 3168(\mathrm{NH})$, $1716(\mathrm{C}=\mathrm{O}) \mathrm{cm}^{-1}$; ESI-MS: Observed $[\mathrm{M}+\mathrm{H}]^{+}=324.7,326.7,328.7$, $[\mathrm{M}+\mathrm{Na}]^{+}=346.7,348.7$, 350.7. Calculated for $\mathrm{C}_{14} \mathrm{H}_{7} \mathrm{Cl}_{3} \mathrm{~N}_{2} \mathrm{O}=325.5$; Anal., found: C, $51.62 ; \mathrm{H}, 2.16 ; \mathrm{Cl}, 32.65 ; \mathrm{N}, 8.62 ; \mathrm{O}, 4.90$. Calculated: C, $51.65 ; \mathrm{H}, 2.17 ; \mathrm{Cl}, 32.67 ; \mathrm{N}, 8.60 ; \mathrm{O}, 4.91 \%$.

5,7-Dichloro-3-(p-tolylimino)indolin-2-one $\left(\mathbf{b}_{14}\right)$ : Yield: 44\%; mp: $230-37^{\circ} \mathrm{C}$ (dec.), ethanol; IR (KBr) $v_{\text {max }} 3162(\mathrm{NH}), 1718(\mathrm{C}=\mathrm{O})$ $\mathrm{cm}^{-1}$; ESI-MS: Observed $\left(\mathrm{M}+\mathrm{H}^{+}\right)=304.8,306.8[\mathrm{M}+\mathrm{Na}]^{+}=326.8,328.8$. Calculated for $\mathrm{C}_{15} \mathrm{H}_{10} \mathrm{Cl}_{2} \mathrm{~N}_{2} \mathrm{O}=305$; Anal., found: $\mathrm{C}, 59.00 ; \mathrm{H}, 3.31 ; \mathrm{Cl}$, 23.22; N, 9.17; O, 5.22. Calculated: C, 59.04; H, 3.30; Cl, 23.24; N, 9.18; $\mathrm{O}, 5.24 \%$.

5,7-Dichloro-3-(4-hydroxyphenylimino)indolin-2-one $\quad\left(b_{15}\right)$ : Yield: $26 \%$; mp: $260-62^{\circ} \mathrm{C}$ (dec.), ethanol; IR (KBr) $v_{\max } 3354(\mathrm{OH})$, $3203(\mathrm{NH}), 1713(\mathrm{C}=\mathrm{O}) \mathrm{cm}^{-1}$; ESI-MS: Observed $[\mathrm{M}+\mathrm{H}]^{+}=306.8,308.8$, $[\mathrm{M}+\mathrm{Na}]^{+}=328.8$, 330.8. Calculated for $\mathrm{C}_{14} \mathrm{H}_{8} \mathrm{Cl}_{2} \mathrm{~N}_{2} \mathrm{O}_{2}=307$; Anal., found: C, 54.74; H, 2.61; Cl, 23.07; N, 9.11; O, 10.40. Calculated: C, $54.75 ; \mathrm{H}, 2.63 ; \mathrm{Cl}, 23.09 ; \mathrm{N}, 9.12 ; \mathrm{O}, 10.42 \%$.

4-(5,7-Dichloro-2-oxoindolin-3-ylideneamino)benzamide $\left(b_{16}\right)$ : Yield: $58 \%$; mp: $22-325^{\circ} \mathrm{C}$ (dec.), ethanol; IR ( $\left.\mathrm{KBr}\right) v_{\max } 3460\left(\mathrm{NH}_{2}\right)$, $3339(\mathrm{~N}-\mathrm{H}), 1733(\mathrm{C}=\mathrm{O}$ Oxindole $), 1662(\mathrm{C}=\mathrm{O}$ benzamide $), 1610(\mathrm{C}=\mathrm{N})$ $\mathrm{cm}^{-1}$; ${ }^{1} \mathrm{H}$ NMR (250 MHz, DMSO-d $) \delta 11.65$ (s, 1H, NH-1), 11.51 (s, $\left.2 \mathrm{H}, \mathrm{CONH}_{2}-4^{\prime}\right), 7.3(\mathrm{~m}), 6.18(\mathrm{~d}, 1 \mathrm{H}, \mathrm{J}=1.8 \mathrm{~Hz}, \mathrm{H}-4)$, mixture of $\mathrm{Z}$ and $\mathrm{E}$ isomers; ${ }^{13} \mathrm{C}-\mathrm{NMR}\left(62.9 \mathrm{MHz}, \mathrm{DMSO}-\mathrm{d}_{6}\right) \delta 112.4,115.8,116.6$, $116.9,117.9,118.4,120.6,120.8,121.3,122.8,123.3,123.9,125.6,126.8$, $127,127.9,129,129.2,130.3,131,133,135,142.2,143.6,146.5,151.2$, 151.6, 152, 153.4, 158.1, 159.4, 163, 167.2, 167.5, 168; ESI-MS: Observed $[\mathrm{M}+\mathrm{H}]^{+}=335$. Calculated for $\mathrm{C}_{15} \mathrm{H}_{9} \mathrm{Cl}_{2} \mathrm{~N}_{3} \mathrm{O}_{2}=334$; Anal., found: $\mathrm{C}$, $53.91 ; \mathrm{H}, 2.70 ; \mathrm{Cl}, 21.24 ; \mathrm{N}, 12.58 ; \mathrm{O}, 9.59$. Calculated: C, 53.91; H, 2.71; $\mathrm{Cl}, 21.22 ; \mathrm{N}, 12.57 ; \mathrm{O}, 9.58 \%$.

3-(4-Chlorophenylimino)-5-(trifluoromethoxy)indolin-2-one $\left(\mathbf{b}_{17}\right)$ : Yield: $43 \%$; mp: $30-240^{\circ} \mathrm{C}$ (dec.), ethanol; IR (KBr) $v_{\max } 3282(\mathrm{~N}-$ $\mathrm{H}), 1746(\mathrm{C}=\mathrm{O}), 1628(\mathrm{C}=\mathrm{N}) \mathrm{cm}^{-1} ;{ }^{1} \mathrm{H}$ NMR $\left(250 \mathrm{MHz}, \mathrm{DMSO}-\mathrm{d}_{6}\right)$ $\delta 11.21$ (s, 1H, NH-1), $7.46(\mathrm{~m}), 7.06(\mathrm{~m}), 6.20$ (d, 1H, J=1.25 Hz; H-4), mixture of $\mathrm{Z}$ and $\mathrm{E}$ isomers; ${ }^{13} \mathrm{C}-\mathrm{NMR}\left(62.9 \mathrm{MHz}, \mathrm{DMSO}-\mathrm{d}_{6}\right) \delta 112$, $112.7,116,117.8,119.3,121.1,127.3,127.4,128.2,129.4,129.5,142.1$, 143.3, 144.7, 146, 147.3, 148.7, 152.9, 154.8, 158.4, 163.3.6; ESI-MS: Observed $[\mathrm{M}+\mathrm{H}]^{+}=342$. Calculated for $\mathrm{C}_{15} \mathrm{H}_{8} \mathrm{ClF}_{3} \mathrm{~N}_{2} \mathrm{O}_{2}=340.7$; Anal., found $\mathrm{C}, 52.92 ; \mathrm{H}, 2.36 ; \mathrm{Cl}, 10.43 ; \mathrm{F}, 16.75 ; \mathrm{N}, 8.21 ; \mathrm{O}, 9.37$. Calculated: C, 52.88; H, 2.37; Cl, 10.41; F, 16.73; N, 8.22; O, 9.39\%.

3-(p-Tolylimino)-5-(trifluoromethoxy)indolin-2-one $\quad\left(b_{18}\right)$ : Yield: 59\%; mp: $66.5-268.5^{\circ} \mathrm{C}$ (with dec.); ethanol; IR (KBr) $v_{\max } 3254$ $(\mathrm{N}-\mathrm{H}), 1741(\mathrm{C}=\mathrm{O}), 1619(\mathrm{C}=\mathrm{N}) \mathrm{cm}^{-1} ;{ }^{1} \mathrm{H}$ NMR $\left(250 \mathrm{MHz}, \mathrm{DMSO}_{6} \mathrm{~d}_{6}\right)$ $\delta 11.3(\mathrm{~s}, 1 \mathrm{H}, \mathrm{NH}-1), 7.15\left(\mathrm{~m}, 6 \mathrm{H}, \mathrm{H}-6,7,2^{\prime}, 3^{\prime}, 5^{\prime}, 6^{\prime}\right), 6.25$ (d, 1H, J=1.3 $\mathrm{Hz}, \mathrm{H}-4), 2.36$ (s, 3H, $\mathrm{CH}_{3}-4$ ), mixture of $\mathrm{Z}$ and $\mathrm{E}$ isomers; ${ }^{13} \mathrm{C}-\mathrm{NMR}$ $\left(62.9 \mathrm{MHz}, \mathrm{DMSO}-\mathrm{d}_{6}\right) \delta 20.41,20.55,111.8,112.6,116.1,117.3,117.8$, $119.9,127.1,128.7,129.9,134.7,142.1,145.7,147.4,154.1,163.4$; ESIMS: Observed $[\mathrm{M}+\mathrm{H}]^{+}=321$. Calculated for $\mathrm{C}_{16} \mathrm{H}_{11} \mathrm{~F}_{3} \mathrm{~N}_{2} \mathrm{O}_{2}=320.2$; Anal., found: C, $60.2 ; \mathrm{H}, 3.45 ; \mathrm{F}, 17.81 ; \mathrm{N}, 8.74 ; \mathrm{O}, 9.97$. Calculated: C, 60.00; $\mathrm{H}, 3.46 ; \mathrm{F}, 17.80 ; \mathrm{N}, 8.75 ; \mathrm{O}, 9.99 \%$.

3-(4-Hydroxyphenylimino)-5-(trifluoromethoxy)indolin-2-one $\left(\mathbf{b}_{19}\right.$ ): Yield: $80 \%$; mp: $30-238^{\circ} \mathrm{C}$ (dec.), ethanol; IR (KBr) $v_{\max } 3314(\mathrm{O}-$ $\mathrm{H}), 3209(\mathrm{~N}-\mathrm{H}), 1732(\mathrm{C}=\mathrm{O}), 1627(\mathrm{C}=\mathrm{N}) \mathrm{cm}^{-1} ;{ }^{1} \mathrm{H}$ NMR $(250 \mathrm{MHz}$, DMSO-d $\left.{ }_{6}\right) \delta 11.13(1 \mathrm{H}, \mathrm{s}, \mathrm{NH}-1), 9.66\left(\mathrm{~s}, 1 \mathrm{H}, \mathrm{OH}-4^{\prime}\right), 7.37(\mathrm{~m}), 6.89(\mathrm{~m})$, $6.60(\mathrm{~d}, 1 \mathrm{H}, \mathrm{J}=1.25 \mathrm{~Hz} ; \mathrm{H}-4)$, mixture of $\mathrm{Z}$ and $\mathrm{E}$ isomers; ${ }^{13} \mathrm{C}-\mathrm{NMR}$ $\left(62.9 \mathrm{MHz}, \mathrm{DMSO}-\mathrm{d}_{6}\right) \delta 111.5,112.4,114.7,115.9,116.3,117.5,119.9$, $123.8,124.8,125.8,126.8,138.7,141,142.1,143.4,145.6,149.1,153.2$, 155.9, 157.1, 158.9, 163.7; ESI-MS: Observed $[\mathrm{M}+\mathrm{H}]^{+}=323$. Calculated for $\mathrm{C}_{15} \mathrm{H}_{9} \mathrm{~F}_{3} \mathrm{~N}_{2} \mathrm{O}_{3}=322.2$; Anal., found: $\mathrm{C}, 55.93 ; \mathrm{H}, 2.84 ; \mathrm{F}, 17.67 ; \mathrm{N}$, 8.69; O, 14.92. Calculated for $\mathrm{C}_{15} \mathrm{H}_{9} \mathrm{~F}_{3} \mathrm{~N}_{2} \mathrm{O}_{3}: \mathrm{C}, 55.91 ; \mathrm{H}, 2.82 ; \mathrm{F}, 17.69$; $\mathrm{N}, 8.69 ; \mathrm{O}, 14.90 \%$.

4-(2-Oxo-5-(trifluoromethoxy)indolin-3-ylideneamino) benzamide $\left(\mathbf{b}_{20}\right)$ : Yield: $49 \%$; mp: $96-304^{\circ} \mathrm{C}(\mathrm{dec}$ ), ethanol; IR $(\mathrm{KBr})$ $v_{\max } 3429\left(\mathrm{NH}_{2}\right), 3121(\mathrm{~N}-\mathrm{H}), 1727(\mathrm{C}=\mathrm{O}$ Oxindole $), 1697(\mathrm{C}=\mathrm{O}$ benzamide), $1608(\mathrm{C}=\mathrm{N}) \mathrm{cm}^{-1} ;{ }^{1} \mathrm{H}$ NMR $\left(250 \mathrm{MHz}\right.$, DMSO-d $\left.\mathrm{d}_{6}\right) \delta 11.22$ (brs, 3H, NH-1, $\left.\mathrm{CONH}_{2} 2^{-}\right), 7.48$ (m, 6H, H-6, 7, 2', 3', 5', 6'), $6.10(\mathrm{~s}, 1 \mathrm{H}$, $\mathrm{H}-4)$, mixture of $\mathrm{Z}$ and $\mathrm{E}$ isomers; ${ }^{13} \mathrm{C}-\mathrm{NMR}\left(62.9 \mathrm{MHz}\right.$, DMSO- $\left.\mathrm{d}_{6}\right)$ $\delta 112,112.7,116,116.8,118,118.3,121.8,122.1,127.4,127.9,129.1$, $130.1,130.8,142.1,143.3,144.8,145.9,151.5,152.5,154.4,158.4$, 163.2, 167.1, 167.6; ESI-MS: Observed $[\mathrm{M}+\mathrm{H}]^{+}=350$. Calculated for $\mathrm{C}_{16} \mathrm{H}_{10} \mathrm{~F}_{3} \mathrm{~N}_{3} \mathrm{O}_{3}=349.26$; Anal., found: $\mathrm{C}, 55.05 ; \mathrm{H}, 2.88 ; \mathrm{F}, 16.30 ; \mathrm{N}, 12.05$; O, 13.72. Calculated: C, 55.02; H, 2.89; F, 16.32; N, 12.03; O, 13.74\%.

3-(4-Chlorophenylimino)-5-fluoroindolin-2-one $\left(\mathbf{b}_{21}\right)$ : Yield: 22\%; mp: 44.6-46 ${ }^{\circ} \mathrm{C}$ (dec.); ethanol; IR (KBr) $v_{\max } 3198(\mathrm{~N}-\mathrm{H}), 1714$ $(\mathrm{C}=\mathrm{O}) \mathrm{cm}^{-1} ;{ }^{1} \mathrm{H}$ NMR $\left(500 \mathrm{MHz}, \mathrm{CDCl}_{3}\right) \delta 7.95(\mathrm{bs}, 1 \mathrm{H}, \mathrm{NH}-1), 7.47(\mathrm{~d}$, 2H, J=8.56; H-3', 5'), 7.36 (m), 6.89 (m), 6.60 (d, 1H , J=1.3 Hz; H-4); ESI-MS: Observed $[\mathrm{M}+\mathrm{H}]^{+}=275$. Calculated for $\mathrm{C}_{14} \mathrm{H}_{8} \mathrm{ClFN}_{2} \mathrm{O}=274$; Anal., found: C, 61.22; H, 2.94; Cl, 12.91; F, 6.92; N, 10.20; O, 5.82 . Calculated: C, 61.22; H, 2.94; Cl, 12.91; F, 6.92; N, 10.20; O, 5.82\%.

5-Fluoro-3-(p-tolylimino)indolin-2-one $\left(\mathbf{b}_{22}\right)$ : Yield: 38\%; mp: 
64-269 ${ }^{\circ} \mathrm{C}(\mathrm{dec}$.$) , ethanol; IR (\mathrm{KBr}) v_{\max } 3256(\mathrm{~N}-\mathrm{H}), 1741(\mathrm{C}=\mathrm{O}), 1652$ $(\mathrm{C}=\mathrm{N}), 1613 \mathrm{~cm}^{-1} ;{ }^{1} \mathrm{H}$ NMR $\left(250 \mathrm{MHz}, \mathrm{DMSO}-\mathrm{d}_{6}\right) \delta 11.03(\mathrm{~s}, 1 \mathrm{H}, \mathrm{NH}-$ 1), $7.15\left(\mathrm{~m}, 6 \mathrm{H}, \mathrm{H}-, 7,2^{\prime}, 3^{\prime}, 5^{\prime}, 6^{\prime}\right), 6.14(\mathrm{dd}, 1 \mathrm{H}, \mathrm{J}=8.5,2.5 \mathrm{~Hz} ; \mathrm{H}-4)$, $2.37\left(\mathrm{~s}, 3 \mathrm{H}, \mathrm{CH}_{3}-4\right)$, mixture of $\mathrm{Z}$ and $\mathrm{E}$ isomers; ${ }^{13} \mathrm{C}-\mathrm{NMR}(62.9 \mathrm{MHz}$, DMSO-d $)_{6} \delta 20.5,111.5,111.9,112.5,112.6,115.9,116,117.4,119.8$ $120.5,120.9,128.7,130,134.6,143.2,147.2,154.3,154.8,158.5,163.5$; ESI-MS: Observed $[\mathrm{M}+\mathrm{H}]^{+}=255$ Calculated for $\mathrm{C}_{15} \mathrm{H}_{11} \mathrm{FN}_{2} \mathrm{O}=254.2$; Anal., found: C, 70.89; H, 4.31; F, 7.45; N, 11.03; O, 6.27. Calculated: C, 70.86; H, 4.36; F, 7.47; N, 11.02; O, 6.29\%.

5-Fluoro-3-(4-hydroxyphenylimino)indolin-2-one $\left(b_{23}\right)$ : Yield: 74\%; mp: $07-320^{\circ} \mathrm{C}$ (dec.), ethanol; IR ( $\left.\mathrm{KBr}\right) v_{\max } 3298,1711(\mathrm{C}=\mathrm{O})$, $1619,1599(\mathrm{C}=\mathrm{N}) \mathrm{cm}^{-1} ;{ }^{1} \mathrm{H}$ NMR $\left(250 \mathrm{MHz}, \mathrm{DMSO}_{\max } \mathrm{d}_{6}\right) \delta 10.97(\mathrm{~s}, 1 \mathrm{H}$, NH-1), 9.66 (s, 1H, OH-4'), 7.26 (m), 6.84 (m), 6.44 (dd, 1H, J=8.5, 2.5 $\mathrm{Hz}$; H-4), mixture of $\mathrm{Z}$ and $\mathrm{E}$ isomers; ${ }^{13} \mathrm{C}-\mathrm{NMR}\left(62.9 \mathrm{MHz}\right.$, DMSO- $\left.\mathrm{d}_{6}\right)$ $\delta 108.6,109,111.1,111.3,111.5,112.3,112.4,114.7,115.9,116,116.2$, $119,119.4,119.9,120.1,120.5,124.6,138.8,140.7,141,142.9,143$, $153.4,154.8,155.8,156.9,158.6,158.9,163.7$; ESI-MS: Observed $[\mathrm{M}+\mathrm{H}]^{+}=257$. Calculated for $\mathrm{C}_{14} \mathrm{H}_{9} \mathrm{FN}_{2} \mathrm{O}_{2}=256.23$; Anal., found: $\mathrm{C}$, 65.68; H, 3.53; F, 7.42; N, 10.91; O, 12.47. Calculated: C, 65.62; H, 3.54; F, $7.41 ; \mathrm{N}, 10.93 ; \mathrm{O}, 12.49 \%$.

4-(5-Fluoro-2-oxoindolin-3-ylideneamino)benzamide $\quad\left(b_{24}\right)$ : Yield: $19 \%$; mp: $77-310^{\circ} \mathrm{C}(\mathrm{dec}$.), ethanol; IR ( $\mathrm{KBr}) v_{\max } 3394\left(\mathrm{NH}_{2}\right)$, $3232(\mathrm{~N}-\mathrm{H}), 1741$ (C=O Oxindole), $1673(\mathrm{C}=\mathrm{O}$ benzamide), 1630 $(\mathrm{C}=\mathrm{N}) \mathrm{cm}^{-1} ;{ }^{1} \mathrm{H}$ NMR $\left(250 \mathrm{MHz}, \mathrm{DMSO}-\mathrm{d}_{6}\right) \delta 11.09$ (s, $\left.1 \mathrm{H}, \mathrm{NH}-1\right)$, $7.94(\mathrm{~m}), 7.33(\mathrm{~m}), 7.06(\mathrm{~m}), 6.92(\mathrm{~m}), 5.97(\mathrm{dd}, 1 \mathrm{H}, \mathrm{J}=8.25,2.5 ; \mathrm{H}-4)$, mixture of $\mathrm{Z}$ and $\mathrm{E}$ isomers; ${ }^{13} \mathrm{C}-\mathrm{NMR}\left(62.9 \mathrm{MHz}, \mathrm{DMSO}-\mathrm{d}_{6}\right) \delta 109.7$, 110.1, 111.7, 112.1, 112.7, 112.8, 115.8, 115.9, 116.9, 118.2, 120.9, 121.3, 127.9, 129.2, 130.8, 143.4, 152.4, 163.3, 167.3, 167.6; ESI-MS: Observed $[\mathrm{M}+\mathrm{H}]^{+}=284$. Calculated for $\mathrm{C}_{15} \mathrm{H}_{10} \mathrm{FN}_{3} \mathrm{O}_{2}=283.2$; Anal., found: $\mathrm{C}$, 63.70; H, 3.55; F, 6.72; N, 14.85; O, 11.33. Calculated: C, 63.60; H, 3.56; F, $6.71 ; \mathrm{N}, 14.83 ; \mathrm{O}, 11.30 \%$.

Sodium(Z/E)-3-(4-chlorophenylimino)-2-oxoindoline-5sulfonate $\left(\mathbf{b}_{25}\right)$ : Yield: $30 \%$; $\mathrm{mp}:>300^{\circ} \mathrm{C}$ (dec.), ethanol; ${ }^{1} \mathrm{H}$ NMR $(250$ MHz, DMSO- $\left.\mathrm{d}_{6}\right) \delta 11.13(1 \mathrm{H}, \mathrm{s}, \mathrm{NH}-1), 7.88$ (dd, $\left.1 \mathrm{H}, \mathrm{J}=6.5 ; \mathrm{H}-\right), 7.61$ $(\mathrm{m}, 1 \mathrm{H}, \mathrm{H}-), 7.51$ (d, 2H, J=8.8 Hz, H-', 6'), $7.06\left(\mathrm{~m}, 2 \mathrm{H}, \mathrm{H}-3^{\prime}, 5^{\prime}\right), 6.86$ $(\mathrm{m}, 2 \mathrm{H}, \mathrm{H}-)$, mixture of $\mathrm{Z}$ and $\mathrm{E}$ isomers.

Sodium-3-(4-hydroxyphenylimino)-2-oxoindoline-5-sulfonate $\left(\mathbf{b}_{26}\right)$ : Yield: $70 \% ; \mathrm{mp}>300^{\circ} \mathrm{C}$ (dec.), ethanol; ${ }^{1} \mathrm{H}$ NMR $(250 \mathrm{MHz}$, DMSO-d $)_{6} \delta 11.01(1 \mathrm{H}, \mathrm{s}, \mathrm{NH}-1), 7.61(\mathrm{dd}, 1 \mathrm{H}, \mathrm{J}=6.5 ; \mathrm{H}-), 7.35$ (d, $2 \mathrm{H}, \mathrm{J}=1.3 \mathrm{~Hz}, \mathrm{H}-$ ), 6.95 (d, J=6.3 Hz, 2H, H-2', 6'), 6.84 (m, H-', 5', 7), mixture of $\mathrm{Z}$ and $\mathrm{E}$ isomers.

Sodium(Z/E)-3-(4-acetamidophenylimino)-2-oxoindoline-5sulfonate $\left(\mathbf{b}_{27}\right)$ : Yield: $22 \%$; $\mathrm{mp}>300^{\circ} \mathrm{C}$ (dec.), ethanol; ${ }^{1} \mathrm{H}$ NMR $(250$ $\left.\mathrm{MHz}, \mathrm{DMSO}-\mathrm{d}_{6}\right) \delta 11.05$ (1H, s, NH-acetamide), 10.13 (s, 1H, NH-), 7.76 (d, 2H, J=1, H-', 6'), 7.63 (d, 1H, J=0.8 Hz, H-), 7.15 (s, 1H, H-4), $6.99\left(\mathrm{~d}, 2 \mathrm{H}, \mathrm{J}=0.8 \mathrm{~Hz}, \mathrm{H}^{-}, 5^{\prime}\right), 6.87(\mathrm{~d}, 1 \mathrm{H}, \mathrm{J}=0.8 \mathrm{~Hz}, \mathrm{H}-)$, mixture of $\mathrm{Z}$ and $\mathrm{E}$ isomers.

\section{Cell culture}

Human ovarian adenocarcinoma (SK-OV3, ATCC no.HTB-77), breast adenocarcinoma (MCF-7, ATCC no.HTB-22), and colon adenocarcinoma (HT-29, ATCC no. HTB-38) cell lines were obtained from American Type Culture Collection. Cells were grown on $75 \mathrm{~cm}^{2}$ cell culture flasks with EMEM (Eagle's minimum essential medium), supplemented with $10 \%$ fetal bovine serum, and $1 \%$ penicillin/ streptomycin solution $(10,000$ units of penicillin and $10 \mathrm{mg}$ of streptomycin in $0.9 \% \mathrm{NaCl}$ ) in a humidified atmosphere of $5 \% \mathrm{CO}_{2}$, $95 \%$ air at $37^{\circ} \mathrm{C}$.

\section{Cell proliferation assay}

Antiproliferative assay was performed using Cell Titer 96 aqueous one solution cell proliferation assay kit (Promega, USA). In a brief, after reaching $75-80 \%$ confluency of cells under microscope, cells (5000 cells/well) were seeded in 96-well microplates in media $(100 \mu \mathrm{L})$. After $24 \mathrm{~h}$, compounds $(50 \mu \mathrm{M})$ were added to wells in triplicate. Doxorubicin $(10 \mu \mathrm{M})$ and DMSO were tested in the assay as positive and negative controls. After $72 \mathrm{~h}$ incubation, CellTiter 96 aqueous solution $(20 \mu \mathrm{L})$ was added into wells. The plate was kept at $37^{\circ} \mathrm{C}$ for $1-2 \mathrm{~h}$. The formazan product absorbance at $490 \mathrm{~nm}$ was measured by 96 -well plate reader. The blank control was recorded by measuring the absorbance at 490 $\mathrm{nm}$ with wells containing medium mixed with CellTiter 96 aqueous solution but no cells. Results were expressed as the percentage of the control (without compound set at 100\%). The results of the inhibition of MCF-7, SK-OV- and HT-9 cells by compounds $\left(\mathrm{a}_{1}-\mathrm{a}_{42}\right)$ and $\left(\mathrm{b}_{1}-\mathrm{b}_{27}\right)$ Series $(50 \mu \mathrm{M})$ after $72 \mathrm{~h}$ incubation is demonstrated in Table 1 . All the experiments were performed in triplicate.

\section{Src kinase activity assay}

The effect of synthesized compounds on the activity of $c$-Src kinase was assessed by Transcreener ${ }^{\oplus} \mathrm{ADP}^{2}$ FI Assay, from Bell Brook Labs, Madison, WI, (catalogue no. 3013-1K) according to manufacturer's protocol. 384-well Low volume Black non-binding surface round bottom microplate was purchased from Corning (\#3676). In summary, the kinase reaction was started in 384-well low volume black microplate with the incubation of the $2.5 \mu \mathrm{L}$ of the reaction cocktail $(0.7 \mathrm{nM}$ of $\mathrm{His}_{6}$-Src kinase domain in kinase buffer) with $2.5 \mu \mathrm{L}$ of prediluted compounds (dissolved in 10\% DMSO, $4 \mathrm{X}$ target concentration) for $10 \mathrm{~min}$ at room temperature using microplate shaker. The reaction cocktail was made using the kinase buffer HEPES (200 mM, pH 7.5), $\mathrm{MgCl}_{2}(16 \mathrm{mM})$, EGTA (8 mM), DMSO (4\%), Brij-35 (0.04\%), and<smiles>[R][R]1ccc2c(c1)C(=C[Al])C(=O)N2</smiles>

\begin{tabular}{|c|c|c|c|c|c|}
\hline No. & $\mathbf{R}$ & $\mathrm{Ar}$ & No. & $\mathbf{R}$ & $\mathrm{Ar}$ \\
\hline$a_{1}$ & $\mathrm{H}$ & $\mathrm{Ph}$ & $a_{22}$ & $\mathrm{H}$ & 5-(4-F-Ph)-3-pyridyl \\
\hline$a_{2}$ & $\mathrm{H}$ & 4-OH-Ph & $a_{23}$ & $\mathrm{H}$ & $-\mathrm{CH}=\mathrm{CH}-\mathrm{Ph}$ \\
\hline$a_{3}$ & $\mathrm{H}$ & $4-\mathrm{OCH}_{3}-\mathrm{Ph}$ & $a_{24}$ & $\mathrm{H}$ & 3-OPh-Ph \\
\hline$a_{4}$ & $\mathrm{H}$ & $3-\mathrm{OCH}_{3}-\mathrm{Ph}$ & $a_{25}$ & $\mathrm{H}$ & 4- $\mathrm{CH}_{3}-\mathrm{CO}-\mathrm{NH}-\mathrm{Ph}$ \\
\hline$a_{5}$ & $\mathrm{H}$ & 4-CN-Ph & $a_{26}$ & $\mathrm{H}$ & 3-F-4- $\mathrm{CH}_{3}-\mathrm{CO}-\mathrm{NHPh}$ \\
\hline$a_{6}$ & $\mathrm{H}$ & $4-\mathrm{NO}_{2}-\mathrm{Ph}$ & $a_{27}$ & $\mathrm{H}$ & $3-\mathrm{Cl}-4-\mathrm{CH}_{3}-\mathrm{CO}-\mathrm{NHPh}$ \\
\hline$a_{7}$ & $\mathrm{H}$ & $3-\mathrm{NO}_{2}-\mathrm{Ph}$ & $a_{28}$ & $\mathrm{H}$ & 2-Thienyl \\
\hline$a_{8}$ & $\mathrm{H}$ & $2-\mathrm{NO}_{2}-\mathrm{Ph}$ & $a_{29}$ & $\mathrm{H}$ & 2-Furyl \\
\hline$a_{9}$ & $\mathrm{H}$ & $4-\mathrm{SCH}_{3}-\mathrm{Ph}$ & $a_{30}$ & $\mathrm{H}$ & 4-Me-Piperazinyl-NBzl \\
\hline$a_{10}$ & $\mathrm{H}$ & 2-Pyridyl & $a_{31}$ & $5-\mathrm{Cl}$ & $4-\mathrm{CH}_{3}-\mathrm{Ph}$ \\
\hline$a_{11}$ & $\mathrm{H}$ & 3-Pyridine & $a_{32}$ & $5-\mathrm{Cl}$ & 4-CN-Ph \\
\hline$a_{12}$ & $\mathrm{H}$ & 4-F-Ph & $a_{33}$ & $5-\mathrm{Cl}$ & $4-\mathrm{OH}-\mathrm{Ph}$ \\
\hline$a_{13}$ & $\mathrm{H}$ & 3-F-Ph & $a_{34}$ & $5-\mathrm{Cl}$ & 4-Br-Ph \\
\hline$a_{14}$ & $\mathrm{H}$ & 2-F-Ph & $a_{35}$ & $5-\mathrm{Br}$ & $4-\mathrm{CH}_{3}-\mathrm{Ph}$ \\
\hline$a_{15}$ & $\mathrm{H}$ & 4-Cl-Ph & $a_{36}$ & $5-\mathrm{Br}$ & 4-CN-Ph \\
\hline$a_{16}$ & $\mathrm{H}$ & 3-Cl-Ph & $a_{37}$ & $5-\mathrm{Br}$ & 4-OH-Ph \\
\hline$a_{17}$ & $\mathrm{H}$ & 2-Cl-Ph & $a_{38}$ & $5-\mathrm{Br}$ & 4-Br-Ph \\
\hline$a_{18}$ & $\mathrm{H}$ & $4-\mathrm{CH}_{3}-\mathrm{Ph}$ & $a_{39}$ & $6-\mathrm{Cl}$ & $4-\mathrm{CH}_{3}-\mathrm{Ph}$ \\
\hline$a_{19}$ & $\mathrm{H}$ & 4-Br-Ph & $a_{40}$ & $6-\mathrm{Cl}$ & 4-CN-Ph \\
\hline$a_{20}$ & $\mathrm{H}$ & 3-Br-Ph & $a_{41}$ & $6-\mathrm{Cl}$ & $4-\mathrm{OH}-\mathrm{Ph}$ \\
\hline$a_{21}$ & $\mathrm{H}$ & $2-\mathrm{Br}-\mathrm{Ph}$ & $a_{42}$ & $6-\mathrm{Cl}$ & 4-Br-Ph \\
\hline
\end{tabular}


2-mercaptoethanol (43 $\mathrm{mM})$. Kinase reaction was started by adding 5 $\mu \mathrm{L}$ of ATP/substrate $(40 \mu \mathrm{M} / 600 \mu \mathrm{M})$ cocktail and incubated for 30 min at room temperature on microplate shaker. Src optimal peptide (AEEEIYGEFEAKKKK) was used as the substrate for the kinase reaction. Kinase reaction was stopped by adding $10 \mu \mathrm{L}$ of the $1 \mathrm{X}$ ADP Detection Mixture to the enzyme reaction mixture and mixed using a plate shaker. The mixture was incubated at room temperature for $1 \mathrm{~h}$, and the fluorescence intensity was measured. The $1 \mathrm{X}$ ADP Detection Mixture was prepared by adding ADP2 Antibody-IRDye ${ }^{\circ}$ QC-1 (10 $\mu \mathrm{g} / \mathrm{mL})$ and ADP Alexa594 Tracer $(8 \mathrm{nM})$ to Stop and Detect Buffer B (1X). Fluorescence Intensity measurements were performed using fluorescence intensity optical module using the excitation of $580 \mathrm{~nm}$ and emission of $630 \mathrm{~nm}$ with band widths of $10 \mathrm{~nm}$ by Optima, BMG Labtechmicroplate reader. $\mathrm{IC}_{50}$ of the compounds were calculated using ORIGIN 6.0 (origin lab) software. $\mathrm{IC}_{50}$ is the concentration of the compound that inhibited enzyme activity by $50 \%$. All the experiments were carried out in triplicate.

\section{Results and Discussion}

The synthetic pathways to prepare 3-arylidene-2-oxindole derivatives $\left(\mathrm{a}_{1-42}\right)$ (Table 1$)$ and 3-arylimino-2-oxindoles $\left(\mathrm{b}_{1-27}\right)$ (Table 2) are depicted in Schemes 1 and 3. 3-Arylidene-2-oxindoles $a_{1}$ to $a_{42}$ were synthesized by the reaction of proper 2-oxindoles with different aryl aldehydes in the presence of piperidine in absolute ethanol (Scheme 1, Table 1).

In the case of compound $\mathrm{a}_{30}$, the aldehyde was synthesized in three steps starting with bromination of 4-tolunitrile, with N-bromosuccinimide (NBS), reaction with 4-methylpiperazine, followed by conversion of nitrile group to aldehyde in the presence of Raney Nickel and formic acid, respectively (Scheme 2).

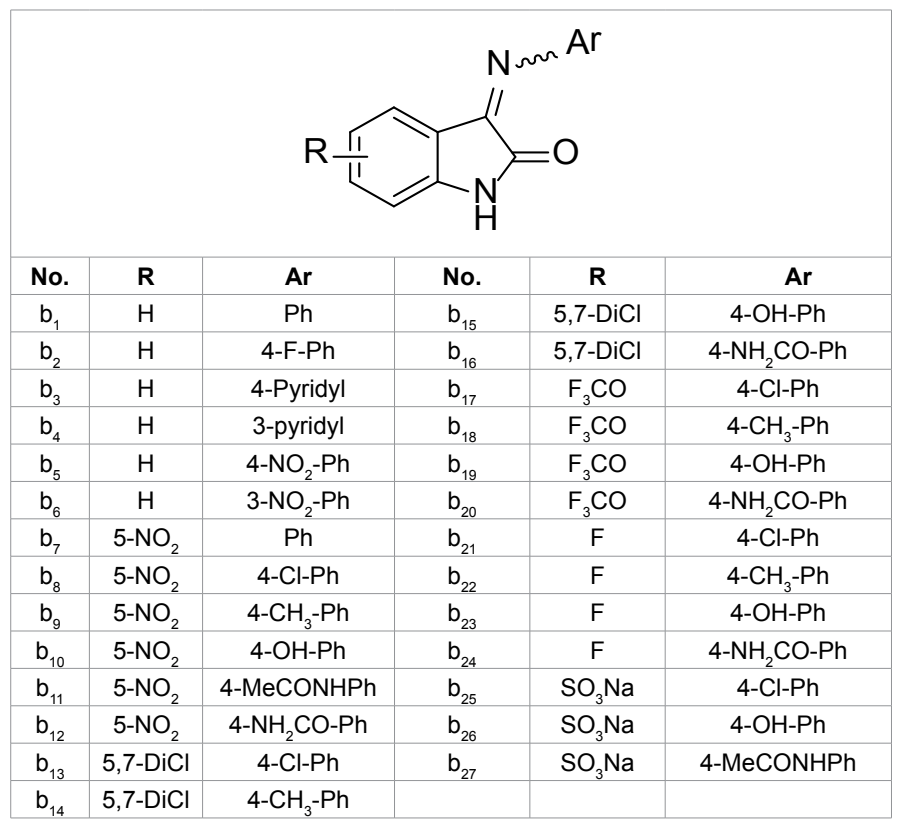

Table 2: Chemical structures of 3-arylimino-2-oxindoles $\left(b_{1-27}\right)$.

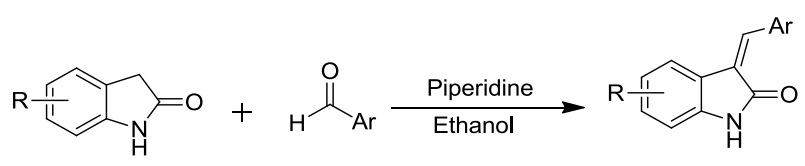

Scheme 1: Synthesis of 3-arylidene-2-oxindole derivatives $\left(a_{1-42}\right)$.

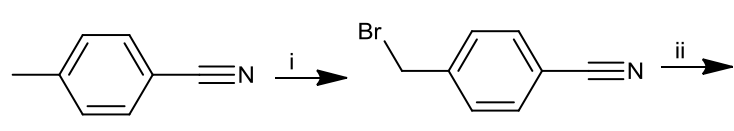

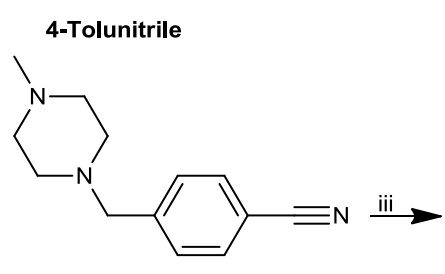

a30- 2 a30- 1

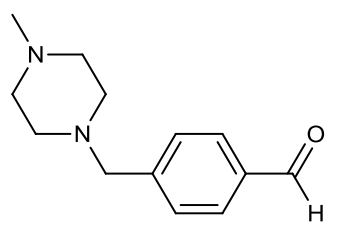

a30- 3
Scheme 2: Synthesis of 4-((4-methylpiperazin-1-yl) methyl)benzaldehyde (a30-3): (i) dibenzoyl peroxide, NBS, CCl4, reflux, $24 \mathrm{~h}$; (ii) 4-methylpiperazine, $\mathrm{CHCl} 3,24 \mathrm{~h}$; (iii) Raney Nickel alloy, formic acid $75 \%$; reflux, $2 \mathrm{~h}$.

The synthesis of 3-arylimino-2-oxindoles was achieved by the reaction of an appropriate isatin with different aryl amines in the presence of catalytic amount of acetic acid in absolute ethanol (Scheme 3, Table 2).

Both arylilidene and arylimine derivatives were obtained as colored crystalline or powdered products, and they were purified by crystallization. Attempts to separate the cis/trans isomers were unsuccessful due to interconvention of cis and trans isomers during the dissolution of the separated compounds in ethanol and other polar solvents as the extracting solvents. The structure of all the synthesized compounds was confirmed by using IR, ${ }^{1} \mathrm{H}$ NMR, ${ }^{13} \mathrm{C}$ NMR, ESI-Mass spectra, and CHNS elemental analysis.

$\mathrm{H}-1$ hydrogen of indole ring was proved to be exchangeable in the presence of few drops of deuterium oxide in ${ }^{1} \mathrm{H}$ NMR spectra. Scrutinizing the ${ }^{1} \mathrm{H}$ NMR for the compounds studied in the present study revealed that for all 3-arylilidene-2-oxindoles and 3-arylimine2-oxindoles, $\mathrm{H}-4$ hydrogen of indole ring appears at around $6 \mathrm{ppm}$ in $\mathrm{E}$ isomers and around 6.8-7 ppm in $\mathrm{Z}$ isomers. This phenomenon can be explained by the anisotropic effect of aryl ring on $\mathrm{H}-4$ hydrogen of indole ring in $\mathrm{E}$ isomers (Figure 3).

All 69 compounds were evaluated for their inhibitory activity against $\mathrm{Src}$ tyrosine kinase and antiproliferative activities. $\mathrm{IC}_{50}$ values of the compounds against Src kinase were determined using a fluorescence intensity assay. The results are shown in Tables 3 and 4 . The most potent compounds against Src kinase were among 3-arylimine-2-oxindole derivatives. Among all compounds, $b_{11}, b_{16}$, and $b_{26}$ showed $\mathrm{IC}_{50}$ values of $5.3,10.4$ and $17 \mu \mathrm{M}$, respectively, against Src kinase (Figure 4). All the compounds were among 3-arylimine-2oxindoles. Only one 3-arylilidene-2-oxindole (compound $\mathrm{a}_{1}$ ) showed modest Src kinase inhibitory activity $\left(\mathrm{IC}_{50}=12.9 \mu \mathrm{M}\right)$.

Both 3-arylilidene-2-oxindoles and 3-arylimine-2-oxindoles were also tested for their cytotoxic effects against three tumor cell lines: human ovarian adenocarcinoma (SK-OV3), breast adenocarcinoma (MCF-7), and colon adenocarcinoma (HT-29) cell lines at $50 \mu \mathrm{M}$ concentration, and the results were obtained in a percentage of inhibition of proliferation (Tables 3 and 4). As it is shown in Table 3 , a number of the 3-arylilidene-2-oxindole derivatives showed the inhibitory potency higher than $50 \%$ in cells Among the three cancer cell lines used in this study, HT-29 was found to be the most sensitive cell line. Nineteen compounds showed greater than 50\% proliferation inhibition in this cell line. Thirteen out of these nineteen compounds are among arylidene derivatives. Thus, it appears that arylidenes are more potent cytotoxic agents against colon cancer cell lines. 


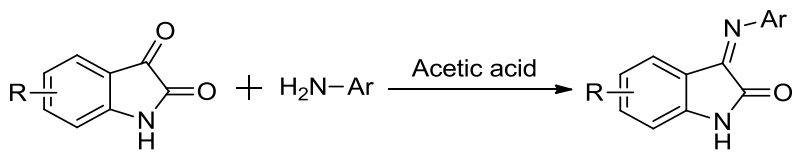

Scheme 3: Synthesis of 3-arylimino-2-oxindoles $\left(\mathbf{b}_{1-27}\right)$.

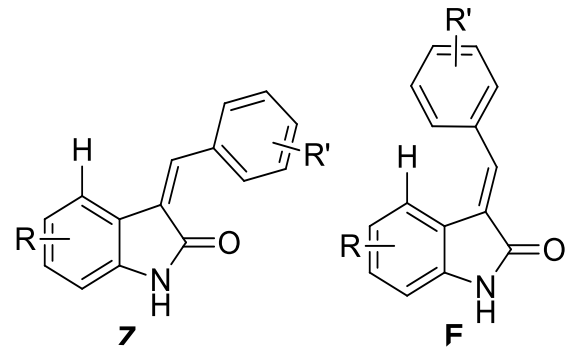

Figure 3: $E$ and $Z$ stereoisomers of oxindoles.<smiles>O=C1Nc2ccccc2/C1=C/c1ccccc1</smiles>

$\mathrm{IC}_{50}=12.9 \mu \mathrm{M}$

a1<smiles>NC(=O)c1ccc(/N=C2\C(=O)Nc3c(Cl)cc(Cl)cc32)cc1</smiles>
b16<smiles>CC(=O)Nc1ccc(/N=C2\C(=O)Nc3ccc([N+](=O)[O-])cc32)cc1</smiles>

$\mathrm{IC}_{50}=5.3 \mu \mathrm{M}$

b11<smiles>O=C1Nc2ccccc2/C1=N/c1ccc(O)cc1</smiles>

$\mathrm{IC}_{50}=\mathbf{1 7 \mu \mathrm { M }}$

b26

Figure 4: Compounds b11, b16, and b26 from 3-arylimine-2-oxindoles and a1 from 3-arylilidene-2-oxindoles were the most potent derivatives against Src kinase.

Compounds $\mathrm{a}_{8}, \mathrm{a}_{20}, \mathrm{a}_{38}$, and $\mathrm{b}_{15}$ showed consistently $>50 \%$ proliferation inhibition against all three cancer cell lines. Among 3-arylidene-2oxindole derivatives, compounds $\mathrm{a}_{22}, \mathrm{a}_{38}$, and $\mathrm{a}_{15}$ were the most potent compounds against HT-29, SK-OV-3, and MCF-7 cells, respectively.

While 5,7-dichloro- derivative b15 in 3-arylimine substituted oxindoles showed high antiproliferative activity against HT-29 and SK-OV-3 cell lines.

Src is a protein tyrosine kinase that is involved in the regulation of multiple signal transduction pathways that are critical to cell survival and proliferation. Here, the Src kinase inhibition assay revealed that four compounds a1, b11, b16, and b26 showed the highest inhibitory activity by $\mathrm{IC}_{50}$ values of $12.9,5.3,10.4$, and $17 \mu \mathrm{M}$, respectively. A comparison among the chemical structures of b11, b16, and b26 showed that all these compounds carry an electron withdrawing group, such as nitro, dichloro, and $\mathrm{SO}_{3} \mathrm{Na}$, as a substituents $\mathrm{R}$ group. Moreover, the presence of an electron donating groups like hydroxyl, methyl, or amine functional groups on the aryl ring was found to be facilitating the

interaction with the binding site. However, as it was described above, there are additional factors such as molecular flexibility, the orientation of chemical functional groups, and proximity to binding sites that contribute to kinase inhibitory potency. Thus, further modeling investigations are required to determine the appropriate functional groups for generating more optimal Src kinase inhibition potency.

Furthermore, the antiproliferative activity of compounds in three different cancer cell lines including HT-29, SK-OV-3, and MCF-7 showed that the activity was cell-dependent. Among all compounds, a8, a38, a20, b15, a22, a36, and a15 showed the highest antiproliferative potency by $70 \%, 67 \%, 70 \%, 76 \%, 76 \%, 76 \%$, and $77 \%$, respectively, in various types of cells. However, a8 and a38 were more potent in SKOV-3 cells compared to other types of cells. A similar pattern was observed for compounds a20 and a22 in HT-29 cells and a15 and b15

\begin{tabular}{|c|c|c|c|c|}
\hline \multirow[b]{2}{*}{ Compound } & \multirow[b]{2}{*}{$\begin{array}{c}\text { C-Src kinase } \\
\text { Inhibition } \mathrm{IC}_{50}(\mu \mathrm{M})^{\mathrm{a}}\end{array}$} & \multicolumn{3}{|c|}{ Proliferation inhibition (\%) } \\
\hline & & HT-29 & SK-OV-3 & MCF-7 \\
\hline$a_{1}$ & 12.9 & 70 & 42 & $\mathrm{NA}^{\mathrm{c}}$ \\
\hline$a_{2}$ & 21 & 52 & $<30$ & NA \\
\hline$a_{3}$ & $N D^{b}$ & $<30$ & $<30$ & $<30$ \\
\hline$a_{4}$ & ND & $<30$ & NA & $<30$ \\
\hline$a_{5}$ & $>300$ & 52 & 40 & 35 \\
\hline$a_{6}$ & ND & 44 & 35 & $<30$ \\
\hline$a_{7}$ & 30.5 & 45 & $<30$ & 35 \\
\hline$a_{8}$ & ND & 62 & 70 & 69 \\
\hline$a_{9}$ & ND & 4 & $<30$ & NA \\
\hline$a_{10}$ & ND & 66 & 52 & $<30$ \\
\hline$a_{11}$ & ND & 40 & 35 & NA \\
\hline$a_{12}$ & ND & 62 & 35 & NA \\
\hline$a_{13}$ & 27.5 & 37 & $<30$ & $<30$ \\
\hline$a_{14}$ & ND & 33 & $<30$ & $<30$ \\
\hline$a_{15}$ & 25.3 & $<30$ & $<30$ & 77 \\
\hline$a_{16}$ & 36.1 & 52 & 47 & 45 \\
\hline$a_{17}$ & $>300$ & 45 & $<30$ & NA \\
\hline$a_{18}$ & ND & 52 & $<30$ & NA \\
\hline$a_{19}$ & ND & NA & $<30$ & $<30$ \\
\hline$a_{20}$ & 35.2 & 67 & 62 & 50 \\
\hline$a_{21}$ & 156.4 & NA & $<30$ & $<30$ \\
\hline$a_{22}$ & 21.2 & 76 & 68 & 35 \\
\hline$a_{23}$ & 65.3 & 45 & 35 & NA \\
\hline$a_{24}$ & 63.1 & 60 & $<30$ & 76 \\
\hline$a_{25}$ & ND & 48 & $<30$ & NA \\
\hline$a_{26}$ & ND & ND & ND & $\mathrm{ND}^{\mathrm{b}}$ \\
\hline$a_{27}$ & 97.2 & 67 & 48 & $<30$ \\
\hline$a_{28}$ & ND & 42 & 37 & $<30$ \\
\hline$a_{29}$ & 95.1 & $<30$ & $<30$ & $<30$ \\
\hline$a_{30}$ & 46.5 & 60 & 60 & $<30$ \\
\hline$a_{31}$ & ND & $<30$ & $<30$ & $<30$ \\
\hline$a_{32}$ & ND & 40 & 32 & $<30$ \\
\hline$a_{33}$ & ND & NA & $<30$ & $<30$ \\
\hline$a_{34}$ & 39.2 & 50 & 35 & 40 \\
\hline$a_{36}$ & 46.2 & 55 & 38 & $<30$ \\
\hline$a_{37}$ & 178.9 & 33 & $<30$ & $<30$ \\
\hline$a_{38}$ & 30.3 & 68 & 76 & 55 \\
\hline$a_{39}$ & $>300$ & $<30$ & $<30$ & $<30$ \\
\hline$a_{40}$ & ND & $<30$ & NA & $<30$ \\
\hline$a_{41}$ & 69.1 & $<30$ & NA & $<30$ \\
\hline$a_{42}$ & 33.7 & 40 & $30>$ & $<30$ \\
\hline
\end{tabular}

aThe concentration that inhibited enzyme activity by $50 \%$; ${ }^{\text {}}$ Not determined; ${ }^{\mathrm{C}} \mathrm{No}$ activity. All data are average of triplicate experiments.

Table 3: The biological activity of compounds $\mathbf{a}_{1-42}$. 


\begin{tabular}{|c|c|c|c|c|}
\hline \multirow[b]{2}{*}{ Compound } & \multirow[b]{2}{*}{$\begin{array}{c}\text { C-Src kinase } \\
\text { Inhibition } \mathrm{IC}_{50}(\mu \mathrm{M})^{\mathrm{a}}\end{array}$} & \multicolumn{3}{|c|}{ Proliferation inhibition (\%) } \\
\hline & & HT-29 & SK-OV-3 & MCF-7 \\
\hline b1 & $\mathrm{ND}^{\mathrm{b}}$ & $<30$ & $<30$ & NA \\
\hline$b_{2}$ & 41.4 & $<30$ & $<30$ & NA \\
\hline$b_{3}$ & ND & 50.0 & NA & 60 \\
\hline $\mathrm{b}_{4}$ & ND & $<30$ & $<30$ & NA \\
\hline$b_{5}$ & 40.5 & 41.0 & $<30$ & $<30$ \\
\hline $\mathrm{b}_{6}$ & ND & $N A^{c}$ & $<30$ & NA \\
\hline$b_{7}$ & ND & $<30$ & NA & NA \\
\hline $\mathrm{b}_{8}$ & ND & 40 & $<30$ & NA \\
\hline$b_{9}$ & ND & NA & $<30$ & $<30$ \\
\hline$b_{10}$ & 36.5 & NA & $<30$ & NA \\
\hline$b_{11}$ & 5.3 & ND & ND & ND \\
\hline$b_{12}$ & 148.4 & $<30$ & NA & $<30$ \\
\hline$b_{13}$ & 29.9 & 32 & $<30$ & 47.0 \\
\hline$b_{14}$ & ND & $<30$ & NA & $<30$ \\
\hline$b_{15}$ & 50.8 & 82.0 & 68 & $<70$ \\
\hline$b_{16}$ & 10.4 & $<30$ & NA & $<30$ \\
\hline$b_{17}$ & ND & NA & NA & $<30$ \\
\hline$b_{18}$ & 23.9 & NA & $<30$ & NA \\
\hline$b_{19}$ & ND & $<30$ & $<30$ & 58.0 \\
\hline$b_{20}$ & 211.8 & $<30$ & NA & $<30$ \\
\hline$b_{21}$ & ND & $<30$ & NA & $<30$ \\
\hline$b_{22}$ & ND & $<30$ & NA & $<30$ \\
\hline$b_{23}$ & 61.1 & $<30$ & NA & $<30$ \\
\hline$b_{24}$ & 27.7 & $<30$ & NA & $<30$ \\
\hline$b_{25}$ & ND & $<30$ & $<30$ & NA \\
\hline$b_{26}$ & 17.0 & 77.0 & NA & 48.0 \\
\hline$b_{27}$ & 27.7 & $<30$ & $<30$ & NA \\
\hline
\end{tabular}

${ }^{a}$ The concentration that inhibited enzyme activity by $50 \%$; ${ }^{\mathrm{N}}$ Not determined; $\mathrm{c}$ No activity. All data are average of triplicate experiments.

Table 4: The biological activity of compounds $b_{1-27}$.

in MCF-7 cells. Comparing the chemical structures of compounds revealed that the majority of them carry electron withdrawing groups including $\mathrm{Br}, \mathrm{Cl}$, and $\mathrm{NO}_{2}$ either as the $\mathrm{R}$ substituent or on the aryl ring. Several factors contribute to the antiproliferative activity of a compound, such as cellular uptake and mechanism of action. Further investigations are needed to determine the mechanism of action like intercalating ability with DNA, radical generating property, apoptosis pathway, and/or cell necrosis.

A direct correlation between Src kinase inhibitory potency and cytotoxicity of all compounds individually was not discovered. However, comparing the results obtained in Src kinase inhibitory and cytotoxic studies revealed the following different trends: In general, arylilidenes were more cytotoxic agents than arylimines, possibly due to the presence of $\alpha, \beta$-unsturated amide and a different cytotoxicity mechanism. On the other hand, arylimines exhibited higher Src kinase inhibitory activity than arylilidenes. We postulate that the arylimines are modestly active against Src kinase and less active in antiproliferative assays possibly because of limited cellular permeability. Compound $a_{1}$ was the only arylilidene derivative with high potency against Src kinase along with modest activities against HT-29 and SK-OV-3 cell lines. Further studies are required to optimize the Src kinase inhibitory and antiproliferative activities of these compounds to find an optimized one that works both as Src kinase inhibitor and antiproliferative agent for potential cancer therapy.

\section{Conclusions}

In conclusion, a number of novel 3-arylilidene- and 3-arylimine-2- oxindole [30] derivatives were synthesized and evaluated for Src kinase inhibitory and antiproliferative activities. In general, arylilidenes exhibited higher antiproliferative activity than arylimines. Compound $\mathrm{b}_{11}$ in 3-arylimine-2-oxindoles showed $\mathrm{IC}_{50}$ values of $5.3 \mu \mathrm{M}$ against Src kinase. These data suggest that 3-arylilidene and 3-arylimine-2oxindole chemical scaffolds can be used as new scaffolds for further structure optimization for generating compounds with higher antiproliferative or Src kinase inhibitory activities, respectively.

\section{Acknowledgement}

We thank National Center for Research Resources, NIH, and Grant Number 8 P20 GM103430-12 for sponsoring the core facility.

\section{References}

1. Hubbard SR, Till JH (2000) Protein tyrosine kinase structure and function. Annu Rev Biochem 69: 373-398.

2. Thomas SM, Brugge JS (1997) Cellular functions regulated by Src family kinases. Annu Rev Cell Dev Biol 13: 513-609.

3. Tsygankov AY, Shore SK (2004) Src: regulation, role in human carcinogenesis and pharmacological inhibitors. Curr Pharm Des 10: 1745-1756.

4. Soriano P, Montgomery C, Geske R, Bradley A (1991) Targeted disruption of the c-src proto-oncogene leads to osteopetrosis in mice. Cell 64: 693-702.

5. Yoneda T, Lowe C, Lee CH, Gutierrez G, Niewolna M, et al. (1993) Herbimycin A, a pp60c-src tyrosine kinase inhibitor, inhibits osteoclastic bone resorption in vitro and hypercalcemia in vivo. J Clin Invest 91: 2791-2795.

6. Kilic Z, Isqor YG, Olgen S (2009) Evaluation of new indole and bromoindole derivatives as pp60(c-Src) tyrosine kinase inhibitors. Chem Biol Drug Des 74 397-404.

7. Fabbro D, Cormick FM (2006) Editors, Protein tyrosine kinases: from inhibitors to useful drugs, 71-93, Humana Press Inc., New Jersey.

8. Homsi J, Cubitt C, Daud A (2007) The Src signaling pathway: a potential target in melanoma and other malignancies. Expert Opin Ther Targets 11: 91-100.

9. Zhou J, Leonard M, Bockstaele EV, Menko AS (2007) Mechanism of Src kinase induction of cortical cataract following exposure to stress: destabilization of cellcell junctions. Mol Vis 13: 1298-1310.

10. Boschelli DH, Wang YD, Ye F, Wu B, Zhang N, et al. (2001) Synthesis and Src kinase inhibitory activity of a series of 4-phenylamino-3-quinolinecarbonitriles. J Med Chem 44: 822-833.

11. Warmuth M, Damoiseaux R, Liu Y, Fabbro D, Gray N (2003) SRC family kinases: potential targets for the treatment of human cancer and leukemia. Curr Pharm Des 9: 2043-2059.

12. Blake RA, Broome MA, Liu X, Wu J, Gishizky M, et al. (2000) SU6656, a selective src family kinase inhibitor, used to probe growth factor signaling. Mo Cell Biol 20: 9018-9027.

13. Guan H, Laird AD, Blake RA, Tang C, Liang C (2004) Design and synthesis of aminopropyl tetrahydroindole-based indolin-2-ones as selective and potent inhibitors of Src and Yes tyrosine kinase. Bioorg Med Chem Lett 14: 187-190.

14. Olgen S, Akaho E, Nebioglu D (2003) Evaluation of indole esters as inhibitors of $\mathrm{p} 60$ (c-Src) receptor tyrosine kinase and investigation of the inhibition using receptor docking studies. J Enzyme Inhib Med Chem 18: 485-490.

15. Olgen S, Akaho E, Nebioglu D (2005) Synthesis and anti-tyrosine kinase activity of 3-(substituted-benzylidene)-, 3-dihydro-indolin derivatives: investigation of their role against p60c-Src receptor tyrosine kinase with the application of receptor docking studies. Farmaco 60: 497-506.

16. Kilic Z, Isgor YG, Olgen S (2009) Synthesis and pp60c-Src tyrosine kinase inhibitory activities of novel indole-3-imine and amine derivatives substituted at $\mathrm{N} 1$ and C5. Arch Pharm (Weinheim) 342: 333-343.

17. Chand K, Prasad S, Tiwari RK, Shirazi AN, Kumar S, et al. (2014) Synthesis and evaluation of c-Src kinase inhibitory activity of pyridin-2 $(1 \mathrm{H})$-one derivatives. Bioorg Chem 53: 75-82.

18. Nasrolahi Shirazi A, Tiwari RK, Brown A, Mandal D, Sun G, et al. (2013) Cyclic peptides containing tryptophan and arginine as Src kinase inhibitors. Bioorg Med Chem Lett 23: 3230-3234.

19. Fallah-Tafti A, Foroumadi A, Tiwari R, Nasrolahi Shirazi A, Hangauer DG, et 
Citation: Mokhtari S, Shirazi AN, Tiwari RK, Parang K, Kobarfard F (2015) Synthesis of 3-Arylidene and 3-Arylimine Oxindole Derivatives and Evaluation of Their Src Kinase Inhibitory and Antiproliferative Activities. Med chem 5: 242-252. doi:10.4172/2161-0444.1000271

al. (2011) Thiazolyl N-benzyl-substituted acetamide derivatives: synthesis, src kinase inhibitory and anticancer activities. Eur J Med Chem 46: 4853-4858.

20. Rao VK, Chhikara BS, Shirazi AN, Tiwari R, Parang K, et al. (2011) 3-substitued indoles: one-pot synthesis and evaluation of anticancer and Src kinase inhibitory activities. Bioorg Med Chem Lett 21: 3511-3514.

21. Rao VK, Chhikara BS, Tiwari R, Shirazi AN, Parang K, et al. (2012) Onepot regioselective synthesis of tetrahydroindazolones and evaluation of their antiproliferative and Src kinase inhibitory activities. Bioorg Med Chem Lett 22: 410-414.

22. Wahl A, Bagard $P$, Haller MA (1909) Chimie organique -sur les iso-indogenides. Compt Rend 149: 132-134.

23. Abramovich RA, Hey DH (1954) Internuclear cyclisation. part VIII. naphth[S:2:1 cdloxindoles. J Chem Soc 1697-1703.

24. Lathourakis GE, Litinas KE (1996) Synthesis and study of 3-(triphenylphosphoranylidene)-2,3-dihydro-1H-indol-2-one. J Chem Soc Perkin Trans 491-493.
25. Ankati H, Akubathini SK, Kamila S, Mukherjee C, D' Mello SR, et al. (2009) Synthesis of 3-benzylidene, 5-substituted 3 benzylidene, 3-hetarylmethylene and 5-substituted derivatives of indolin-2-ones. Open Org Chem J 3: 1-10.

26. Olgen S, Gotz C, Jose S (2007) Synthesis and biological evaluation of 3-(substituted-benzylidene)-,3-dihydro-indolin derivatives as human protein kinase CK2 and p60 (c-Src) tyrosine kinase inhibitors. J Biol Pharm Bull 30 715-718.

27. Schlenoff JB, Johnson KF, Dharia J, Gao F (1996) New fluors for radiationtolerant scintillators, Florida State University. Patent No: US005552551A.

28. Sairam P, Puranik R, Kelkar AS, Sasikiran S, Veerender M, et al. (2003) The ester and amide derivatives of 4-(4-methyl piperazinomethyl) benzoic acid. Synth Commun 33: 3597-3605.

29. van Es T, Staskun B (1988) Aldehydes from aromatic nitriles: 4-formylbenzenesulfonamide. Org synth Coll 6: 631.

30. Hu Y, Kang H, Zeng B, Wei P, Huang H (2008) Facile synthesis of 3-arylidene-,3 dihydroindol-2-ones catalysed by a brønsted acidic ionic liquid. J Chem Res 11 : 642-643. 